$12-2010$

\title{
The Visible Hand: Coordination Functions of the Regulatory State
}

Robert B. Ahdieh

Texas A\&M University School of Law, ahdieh@law.tamu.edu

Follow this and additional works at: https://scholarship.law.tamu.edu/facscholar

Part of the Administrative Law Commons, Law and Economics Commons, and the Law and Society Commons

\section{Recommended Citation}

Robert B. Ahdieh, The Visible Hand: Coordination Functions of the Regulatory State, 95 Minn. L. Rev. 578 (2010).

Available at: https://scholarship.law.tamu.edu/facscholar/1187

This Article is brought to you for free and open access by Texas A\&M Law Scholarship. It has been accepted for inclusion in Faculty Scholarship by an authorized administrator of Texas A\&M Law Scholarship. For more information, please contact aretteen@law.tamu.edu. 


\title{
Article
}

\section{The Visible Hand: Coordination Functions of the Regulatory State}

\author{
Robert B. Ahdieh ${ }^{\dagger}$
}

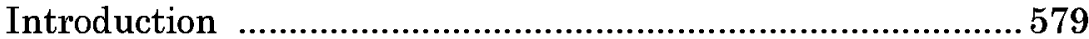

I. The Coordination Economy ….......................................584

II. Defection, Coordination, and the Regulatory State .........598

A. The Dilemma of Defection and the Regulatory

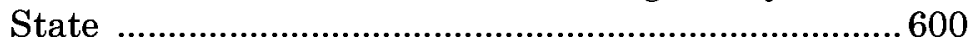

B. From Defection to Coordination .................................603

C. Dilemmas of Coordination .........................................607

III. The New Regulation ..................................................617

A. From Incentives to Expectations ..............................618

1. Regulation Beyond Coercion .................................618

2. Information as Regulation ...................................622

3. The Behavioral Dimensions of Coordination .......625

B. From Dominant Strategies to Multiple Equilibria ....627

1. Multiple Equilibria, Barriers to Entry, and Lock-in in Coordination .........................................628

2. Cues, Seeds, and Nudges: The Changing Nature of Modern Regulation ...............................631

3. Regulation and Coordination in Innovation .........633

+ Professor of Law and Director, Center on Federalism \& Intersystemic Governance, Emory University School of Law. Many thanks to Ken Abbott, Hope Babcock, Bill Bratton, Rick Brooks, Bill Buzbee, Anupam Chander, Cary Coglianese, Lee Cronk, Jeff Gordon, Matt Gerke, Tom Ginsburg, Joanne Gowa, Michael Halberstam, Vicki Jackson, Kurt Kastorf, Bob Keohane, Greg Klass, Beth Leech, David Luban, Eric Maskin, Richard McAdams, Marc Miller, Curtis Milhaupt, Barry O'Neill, Barak Orbach, Frank Partnoy, Ed Rubin, Robert Schapiro, Joanne Scott, Bill Simon, Jason Solomon, Susan Sturm, and Kathy Zeiler for their helpful counsel. I am likewise grateful to workshop participants at Arizona State, Columbia, Georgetown, McGeorge, Seattle, Seton Hall, Tel Aviv University, University of British Columbia, University of California, Davis, and Wisconsin law schools, and at the Institute for Advanced Study and the Annual Meeting of the Law and Society Association, for their valuable insights on earlier iterations of this ongoing project. Copyright (C) 2010 by Robert B. Ahdieh. 
4. Regulatory Coordination and the Evolution of Cooperation

C. From Individuals to Groups .....................................637

D. Crisis and Coordination in the Financial Markets ....642

Conclusion

\section{INTRODUCTION}

We live in a coordination economy. As one surveys the myriad challenges of modern social and economic life, an everincreasing proportion is defined not by the need to reconcile competing interests, but by the challenge of getting everyone on the same page. Conflict is not absent in these settings. It is not, however, the determinative factor in shaping our behaviors and resulting interactions. That essential ingredient, instead, is coordination.

No less an episode than the recent financial crisis helps to highlight as much. For all the ink spilt over Bernie Madoff's mind-boggling Ponzi scheme, the extreme risk-taking behavior of AIG's Financial Products unit, and the massive executive bonuses awarded before, during, and after the market's collapse, none of these indisputably bad acts goes to the heart of the financial crisis. What made the crisis a crisis, rather, was a failure of coordination. Having previously gotten too far ahead of the market, the expectations of banks and other sources of capital abruptly fell behind it. A paralyzing credit crunch-a classic coordination failure-followed, with all the consequences we have since lived through. ${ }^{1}$

Consider the equally familiar example of the Internet. Surely few technologies have more dramatically altered social and economic life in recent decades than the World Wide Web. ${ }^{2}$ Like the financial markets, the Internet turns out to be a massive exercise in coordination. The Internet backbone, the common technical standards on which it relies, and even the core business models emerging out of it, rely on the coordination of

1. See generally Chrystia Freeland, The Credit Crunch According to Soros-Part I, FIN. TIMES, Jan. 31, 2009, available at http://www.ft.com/cms/s/0/ aaadcffe-ef37-11dd-bbb5-0000778fd2ac.html (discussing the events leading up to the current financial crisis and the impact of the crisis).

2. See, e.g., Robert E. Litan, The Internet Economy, FoREIGN POL'Y, Mar.-Apr. 2001, at 16 (suggesting that the Internet may save Americans $\$ 200$ billion annually). 
hundreds, thousands, and millions of users, variously acting as both producers and consumers. ${ }^{3}$

The list goes on, from the Obama Administration's aspirations to modernize the electricity grid and lay the foundation for a high-speed rail system, to the encouragement of scientific innovation, to changing forms of musical creativity, to the rise of social networks, in each of these cases, the critical task is not overcoming conflicting interests-the conventional aim in our efforts to maximize social and economic welfare-but coordinating the choices of large numbers of individuals and institutions. Much of the vaunted "New Economy" turns out to be a coordination economy. ${ }^{4}$

Maintaining financial stability, developing the Internet, building telecommunications, electricity, and transportation networks, and increasing innovation, however, have proven to be significant challenges for policymakers. Even as the reach of the Internet has extended dramatically, questions about the appropriate scope and nature of its regulation have largely paralyzed public efforts to foster its growth and development. ${ }^{5}$ As the pace of innovation in the pharmaceutical industry and other sectors has fallen off, we have likewise struggled with how best to "promote the Progress of Science and useful Arts."6 Policymakers have also sat back as the U.S. electricity grid has fallen out-of-date, ${ }^{7}$ and the country has fallen well behind its

3. See LAWRENCE LESSIG, Remix: MAKING ART AND COMMERCE Thrive IN THE HYBRID ECONOMY 132-37 (2008) (describing the use of consumer data by Amazon.com, Google, and Netflix to generate incrementally improved search results and recommendations).

4. Cf. Steve Lohr, Computer Age Gains Respect of Economists, N.Y. TIMES, Apr. 14, 1999, at A1, available at 1999 WLNR 3005400 (highlighting the role of "electronic links with customers and suppliers" in speeding business expansion).

5. See Jay P. Kesan \& Andres A. Gallo, Optimizing Regulation of Electronic Commerce, 72 U. CIN. L. REV. 1497, 1503 (2004) (proposing a mixed public-private regulatory regime to account for the unique problems posed by the Internet); Philip J. Weiser, The Future of Internet Regulation, 43 U.C. DAVIS L. REV. 529, 536-37 (2009) (suggesting a "co-regulation" model for the Internet); Timothy S. Wu, Cyberspace Sovereignty?-The Internet and the International System, 10 HARV. J.L. \& TECH. 647, 649-56 (1997) (discussing and responding to scholars who question the ability to regulate the Internet).

6. U.S. CONST. art. I, § 8, cl. 8; see also Jonathan Huebner, A Possible Declining Trend for Worldwide Innovation, 72 TECH. FORECASTING \& SoC. CHANGE 980, 985 (2005) (noting a decline in the rate of new inventions).

7. Drew Thornley, Op-Ed., America Needs to Charge Feds with Improving Electrical Grid, S.F. EXAMINER, Sept. 21, 2010, http://www.sfexaminer.com/ opinions/columns/oped_contributors/america-needs-to-charge-feds-with-improving -electrical-grid-103503154.html. 
peers in the construction of high-speed rail lines. ${ }^{8}$ Perhaps most striking was the halting-even fumbling-response to the financial crisis at its earliest stages. ${ }^{9}$

At first glance, our ambivalence, inertia, and confusion in the regulation of these varied arenas might seem unrelated. At least in part, however, the challenge in each area can be traced to a failure to engage with the role of regulation in facilitating coordination. This Article seeks to address that gap.

Coordination is commonly understood as the function of the market. The "invisible hand" - or less metaphorically, the determination of equilibrium price by the aggregation of supply and demand-is the dominant mechanism of coordination in a market economy. ${ }^{10}$ When coordination occurs at one point versus another, or even fails to occur at all, we have consequently not been conditioned to see the possibility of a coordination failure. Rather, we see the market as having spoken. ${ }^{11}$

Optimal coordination will not always emerge, however, as if led "by an invisible hand." 12 Even in settings where coordination is essential, it may fail to materialize, may emerge in a form that could have been improved upon, or may not be amenable to displacement despite the world changing around it. ${ }^{13}$ There consequently may be a role for regulation in encouraging, fostering, and facilitating efficient coordination in the financial markets, on the Internet, and in technological innovation. ${ }^{14}$

Where the impetus for regulation lies in the demands of coordination-as distinct from more familiar externalities and

8. See Keith Bradsher, A High-Speed Economy, N.Y. TIMES, Feb. 13, 2010, at B1, available at 2010 WLNR 3067192.

9. See Alan S. Blinder, Six Blunders En Route to a Crisis, N.Y. TIMES, Jan. 25, 2009, at BU7, available at 2009 WLNR 1435200.

10. AdAM SMiTh, The Wealth of NATIONS, BoOKS IV-V 1-12, 32 (Andrew Skinner ed., Penguin Books 1999) (1776).

11. In his Pulitzer Prize-winning account of what might be cast as a coordination function for managerial administration in modern business, historian Alfred Chandler highlighted just the type of counterpoint with the invisible hand that I aim to suggest in this Article. See ALFRED D. CHANDLER, JR., THE VISIBLE HAND: THE MANAGERIAL REVOLUTION IN AMERICAN BUSINESS 1 (1977).

12. SMITH, supra note 10 , at 32 .

13. See infra Parts II.C, and III.B.1.

14. See Robert W. Crandall, Brookings Inst., Extending DeregULATION: MAKE THE U.S. ECONOMY MORE EFFICIENT (2007), available at http:// www.brookings.edu/ /media/Files/Projects/Opportunity08/PB_Deregulation_ Crandall.pdf (prepared for the Brookings Institute's "Opportunity 08 " project). 
collective action problems ${ }^{15}$ - the form of any such intervention will likewise vary. One can expect such interventions to emphasize the shaping of expectations rather than the alteration of incentives, to be intertwined with questions of information and knowledge, and to focus on the dynamics of groups. Coordination-driven regulation in the financial markets, the Internet, or standard setting thus emerges as a kind of "New Regulation." 16

In Part I, I posit the rise of a coordination economy. To begin, I draw attention to areas of the social and economic order in which coordination is critical. I then highlight recent scholarship by Yochai Benkler, Michael Heller, Larry Lessig, and others that, while they do not explicitly frame it as such, focuses on just the dynamic of coordination I emphasize herein. ${ }^{17}$ Part II turns to a strand of game theory largely overlooked by regulation theorists to offer a theory of the role of regulation in coordination settings. While legal scholars have exhibited a near obsession with the Prisoner's Dilemma, ${ }^{18}$ other games turn out to be no less useful in the analysis of law. In particular, coordination games offer valuable insight into the patterns of interaction studied in this Article and highlight distinct ways in which coordination may require regulatory intervention,

15. Cf. STEPHEN G. BREYER, REGULATION AND ITS REFORM 15-35 (1982) (discussing "traditional" reasons for regulation such as control of monopolies, limits on rent seeking, and "compensating for externalities"); Jon D. Hanson \& Kyle D. Logue, The Cost of Cigarettes: The Economic Case for Ex Post Incentive-Based Regulation, 107 YALE L.J. 1163, 1253 (1998) (summarizing one argument for requiring smokers to internalize the social costs of smoking).

16. See infra Part III. I do not mean to suggest that coordination has displaced the worries behind our regulatory interventions in areas including environmental law, workplace safety, and securities trading. The conflicting incentives that motivate regulation in these spheres are no less important today than a century ago. The dynamics at work in the financial markets, the Internet, the encouragement of innovation, and elsewhere simply make coordination a crucial concern as well. I likewise appreciate the mix of coordination and conflict that will often be present. The excess risk taking that helped to produce the recent financial crisis, for example, is properly understood as grounded in conflicting interests and attendant negative externalities, notwithstanding the fact that the crisis it generated was defined by a failure of coordination. See infra notes 34-38 and accompanying text.

17. See infra notes $60-81$ and accompanying text.

18. See, e.g., Richard H. McAdams, Beyond the Prisoners' Dilemma: Coordination, Game Theory, and Law, 82 S. CAL. L. REV. 209, 214 (2009). For a concise description of the Prisoner's Dilemma, see WILLIAM POUNDSTONE, PRISONER'S DILEMMA 103-05 (1992). 
beyond the market failures regulation theory has commonly emphasized. 19

If coordination is increasingly central to the social and economic order, and will sometimes favor a role for regulation, what form can we expect such regulation to take? While a full account of the latter must depend on its analysis in individual policy settings, ${ }^{20}$ Part III explores the broad outlines of a regulatory regime attuned to coordination. I consider, in turn, the implications of three shifts in emphasis as we move away from settings characterized by coordination games rather than Prisoner's Dilemma dynamics. First, the focus moves from relevant actors' incentives to their expectations. Second, players' choice of behavior is characterized by multiple equilibria rather than dominant strategies. Finally, a heightened emphasis on groups supplements our conventional focus on individuals. Ultimately, these shifts point to the prospect of a regulatory regime that is more selective in its use of coercion, is more oriented to information production and the encouragement of innovation, and is more willing to embrace broader forms of both private regulation and potentially reviewable state action.

I should note an important caveat regarding the normative implications of the analysis herein. My argument is that we need to recognize coordination as an increasingly important impetus for regulatory action. But one should not take this as an assertion of the presumptive efficiency of such intervention. State actors may not be especially good, for example, at setting technological standards. Likewise, they may be prone to capture, and may encourage lock-in of an early mover's choice of standards, even absent any such bias. ${ }^{21}$ This is all the more reason for us to be sensitive to the dynamics of coordination in the modern social and economic order and to its implications for the regulatory state. A far broader range of state action might thus be judged to deserve review under the Administrative Procedure Act once we recognize the coordinative role of regulation. ${ }^{22}$

19. For a description of coordination games and their differences from Prisoner's Dilemma games, see McAdams, supra note 18, at 218-24.

20. See Edward L. Rubin, The New Legal Process, the Synthesis of Discourse, and the Microanalysis of Institutions, 109 HARV. L. REV. 1393, 1425-26 (1996) (emphasizing the need for "microanalysis of institutions" in seeking to properly understand social and economic phenomena of interest to legal scholars).

21. See infra III.B.1.

22. See infra note 191 and accompanying text. A proper appreciation of 
More generally, by attending to the coordination functions of regulation, some of the confusion and paralysis that have characterized our regulatory approach to the Internet, to hightech innovation, and to the financial markets may be alleviated. Our inability to regulate effectively in these areas might thus be traced to our misconceptions of the actual function, and consequently the appropriate form, of regulation in these and other coordination spheres.

Yet more broadly, an appreciation of the coordination functions of regulation may speak to some of the uncertainty in our positive accounts of the regulatory state: Is it expanding or shrinking? Is it growing stronger or weaker? Is the public sector becoming more private or the private sector more public? It may also shed light on the normative and prescriptive questions that ensue: When is regulatory intervention appropriate? What form should it take? And, most abstractly, what should the modern administrative state look like?

To address these questions, we must acknowledge the changing demands on our regulatory apparatus. In important spheres, the modern administrative state may increasingly be a coordination state. This is not a story of deregulation or small government, nor is it one of reregulation or big government. Rather, the question to which it speaks "is not whether our Government is too big or small, but whether it works."23

\section{THE COORDINATION ECONOMY}

Viewed through the prism of law, we seem to live in a world defined by conflict. It is in the regulation of conflicts concerning preferences, interests, and resulting incentives that law is commonly seen to serve its role. Across myriad aspects of our social and economic life, however, the critical challenge is not negotiating conflicting interests, but getting everyone on

the coordination functions of regulation likewise counsels reconsideration of the "market participant" exemption in our Dormant Commerce Clause jurisprudence. See generally Dan T. Coenen, Untangling the Market-Participant Exemption to the Dormant Commerce Clause, 88 MICH. L. REV. 395, 398-400 (1989); infra notes 260-61 and accompanying text.

23. AdMINiSTRATION OF BARACK H. OBAMA, 2009 InAUgURAL ADDRESS (Jan. 20, 2009), available at http://www.gpoaccess.gov/presdocs/2009/DCPD 200900001.pdf. As a popular newsmagazine framed recent debates over regulatory reform: "All of this is unfolding in an economy that can no longer be understood, even in passing, as the Great Society vs. the Gipper." John Meacham \& Evan Thomas, We Are All Socialists Now, NewSwEEK, Feb. 16, 2009, at 23, available at 2009 WLNR 2549898. 
the same page. In these settings, the operative task is to coordinate individuals' expectations of one another by way of knowledge, information, and, perhaps, even regulation.

In recent years, such coordination has become an increasingly critical aspect of life in modern industrialized nations. Consider the most consequential social and economic event in recent memory: the financial crisis of the last several years. Much of our attention to the crisis has focused on grotesque incidents of fraud perpetrated by the Bernie Madoffs and Allan Stanfords of the financial industry, on dramatic risk taking by financial institutions such as AIG's Financial Products unit, and on badly designed and overly generous executive bonuses. ${ }^{24}$ The heart of the financial crisis, however, was a failure of coordination.

Operation of the modern credit markets depends on collective dynamics of lending and investment. ${ }^{25}$ Consider the investment that stands behind commercial lending today-banks' securitization of relevant debts and sale of the resulting securities to hedge fund and private equity investors. ${ }^{26}$ The abrupt shutdown of this market triggered the recent credit crunch.

24. See, e.g., Edmund L. Andrews \& Vikas Bajaj, Amid Fury, U.S. Is Set to Curb Executives' Pay After Bailouts, N.Y. TIMES, Feb. 4, 2009, at A1, available at 2009 WLNR 2059127 (discussing the Obama Administration's response to excessive executive pay); Beth Healy, Madoff Takes Step Toward Guilty Plea, BOS. GLOBE, Mar. 7, 2009, at 5, available at 2009 WLNR 4389072. This is not to suggest that dynamics of defection are irrelevant to an understanding of financial crises. As noted above, the payment of massive bonuses, fraudulent behavior, and high-risk lending are all incidents of defection from socially optimal equilibria. Particularly the last of these-risky lending and investment practices by financial sector firms - can be understood to have been an important impetus behind the recent financial crisis. More broadly, in fact, patterns of defection may often be ex ante factors in prompting financial crises. For the reasons outlined above, however, the ex post alleviation of such crises turns on a dynamic of coordination.

25. See Bianna Golodryga, Financial Crisis, Bailout Has Ripples Past Wall Street, ABCNEWS.COM, Sept. 28, 2008, http://abcnews.go.com/GMA/story? id=5902773 (quoting Bush Administration spokesperson Dana Perino: "If no one in the financial community trusts each other to lend money, then we're going to have a complete and total financial collapse"); see also Bob Davis \& Carrick Mollencamp, Financial Protectionism is Latest Threat to Global Recovery, WALL ST. J., Feb. 2, 2009, at A2 (noting the retreat of various national banking communities into defensive stances in the aftermath of the 2008 financial crisis).

26. See Vikas Bajaj, Lending Locked, U.S. Tries a Trillion-Dollar Key, N.Y. TIMES, Feb. 20, 2009, at A1, available at 2009 WLNR 3328102 ("Most banks no longer hold the loans they make .... Instead, the loans are bundled into securities that are sold to investors, a process known as securitization."). 
Deprived of the ability to move existing loans off their balance sheets, banks ceased to issue new ones. ${ }^{27}$

Why was there such an abrupt collapse in the market for bank debt? The willingness of any given hedge fund or private equity firm to invest, it turns out, depends on the willingness of others to invest as well. Unprofitable as withholding credit and investments are for the banking industry and the investors that stand behind it, it is preferable to lending and investing alone. ${ }^{28}$ When it comes to the credit markets, coordinated entry, coordinated participation, and coordinated exit are consequently the norm. ${ }^{29}$

To appreciate this, consider the dynamic at work in a bank run. In the latter, depositors' simultaneous attempts to withdraw funds bankrupts a bank, given its retention of only a limited proportion of its liabilities in reserve. ${ }^{30}$ As modeled by Diamond and Dybvig, the dispositive characteristic of a bank run is the presence of multiple equilibria. ${ }^{31}$ In the superior equilibrium, depositors maintain their deposits with the bank as they expect others to as well, and they are thereby assured of their ability to withdraw their funds on whatever future date they need them. This allows others to withdraw at earlier dates, thereby generating an efficient distribution of risk among all depositors. ${ }^{32}$ In the inferior equilibrium, by contrast, confidence has been undermined. Each depositor expects others to withdraw and therefore seeks withdrawal of her own deposits as well. The result is a dynamic of coordination. Where de-

27. Id.

28. See Golodryga, supra note 25.

29. Scholars have explored this dynamic of interlinkage and resulting interdependency in the financial markets as a form of "systemic risk." See Steven L. Schwarcz, Systemic Risk, 97 GEO. L.J. 193, 198-201 (2008).

30. This is the essential structure of bank finance in a system of fractional reserve banking. See Henry N. Butler \& Jonathan R. Macey, The Myth of Competition in the Dual Banking System, 73 CORNELL L. REV. 677, 694-96 (1988); Mark J. Roe, Foundations of Corporate Finance: The 1906 Pacification of the Insurance Industry, 93 CoLUM. L. REV. 639, 647 n.22 (1993); Albert J. Boro, Jr., Comment, Banking Disclosure Regimes for Regulating Speculative Behavior, 74 CALIF. L. REV. 431, 434-35 (1986).

31. See Douglas W. Diamond \& Philip H. Dybvig, Bank Runs, Deposit Insurance, and Liquidity, 91 J. POL. ECON. 401, 402 (1983) ("This vulnerability occurs because there are multiple equilibria with differing levels of confidence."). Confirming the mistaken emphasis on the Prisoner's Dilemma versus coordination games suggested infra Part II, bank runs have often been mischaracterized as Prisoner's Dilemma games by legal scholars. See e.g., McAdams, supra note 18 , at $216-17$.

32. See Diamond \& Dybvig, supra note 31 , at 403. 
positors coordinate around a "maintain deposit" equilibrium, returns are optimized; when they coordinate around a "withdraw deposit" equilibrium, we have a financial crisis. ${ }^{33}$

The recent crisis saw important examples of such bank runs, including the cases of Bear Stearns and Northern Rock. ${ }^{34}$ The critical dynamic in the crisis was not one of bank runs, however, but rather a credit crunch, which abruptly curtailed both individual and institutional access to capital.35 At its heart, however, the pattern was the same. Over the course of 2008 and 2009, lenders resisted lending and investors resisted investing on the expectation that others would not be lending or investing either.

A credit crunch thus turns out to be a multiple equilibrium or coordination dynamic akin to that of a bank run. ${ }^{36}$ As in the latter, banks can be expected to coordinate around either a strategy of lending funds or of withholding them. ${ }^{37}$ Likewise, depending on relevant expectations, hedge funds and private equity investors will coordinate around a policy of investment or noninvestment (or even divestment). ${ }^{38} \mathrm{~A}$ credit crunch and

33. See id. at 403-04 (noting the genesis of bank runs is "a shift in expectations").

34. See Jane Kamensky, Boom and Bust: It's the American Way, L.A. TIMES, July 20, 2008, at 1, available at 2008 WLNR 13528841 (noting the corrosive effects of an expanding "circle of mistrust" in recent bank failures); Robin Sidel, The Week that Shook Wall Street: Inside the Bailout of Bear Stearns, WALL ST. J., Mar. 18, 2008, at A1 (highlighting how the spread of "negative rumors" caused investors to withdraw funds from Bear Stearns and erode its otherwise strong capital reserve).

35. See Daniel Indiviglio, Another Shot at the Credit Crunch, FORBES.COM, Mar. 3, 2009, http://www.forbes.com/2009/03/03/talf-fed-lending -business-washington_talf_print.html (noting the creation of a government program to relieve the credit crunch).

36. See Russell Cooper \& Andrew John, Coordinating Coordination Failures in Keynesian Models, 103 Q.J. ECON. 441, 447 (1988) (" $[\mathrm{H}]$ ighlight[ing] the connection between strategic complementarity and multiplicity of equilibria."); Paul R. Masson, Multiple Equilibria, Contagion, and the Emerging Market Crises 5-11 (Int'l Monetary Fund, IMF Working Paper WP/99/164, 1999) (discussing three distinct accounts of multiple equilibria in financial markets); see also id. at 3 ("[M]odels with multiple equilibria . . . square better with the stylized facts of global financial markets."). The same might be said of the dynamics at work among creditors in the face of a potential bankruptcy. See McAdams, supra note 18, at 218 n.32.

37. See Masson, supra note 36, at 6 ("[I]f each bank believes that all other banks will stop lending, all banks will stop lending." (quoting Jeffrey Sachs, Theoretical Issues in International Borrowing 32 (Princeton Studies in Int'1 Fin. Working Paper No. 54, 1984))).

38. Some have characterized financial crises as arising out of "strategic complementarities"-a dynamic of positive feedback, in which payoffs arise 
other forms of financial crises thus might be seen as simply the supply-side corollary of the demand-side coordination failure we see in a bank run. ${ }^{39}$ Maintaining the stability of the markets and avoiding financial crises consequently emerge as complex exercises in coordination. ${ }^{40}$

from choices that match those of other market participants. See Jeremy I. Bulow et al., Multimarket Oligopoly: Strategic Substitutes and Complements, 93 J. POL. ECON. 488, 491-97 (1985); Cooper \& John, supra note 36, at 447. The same holds true for accounts of the financial markets. Compare Robert B. Ahdieh, Law's Signal: A Cueing Theory of Law in Market Transition, 77 S. CAL. L. REV. 215, 223-25 (2004) (discussing how financial markets are shaped by "network externalities"), and Michael L. Katz \& Carl Shapiro, Network Externalities, Competition, and Compatibility, 75 AM. ECON. REV. 424, 424 (1985) (same), with JOHN MAYNARD KEYNES, THE GENERAL THEORY OF EMPLOYMENT INTEREST AND MONEY 156 (1936) (comparing markets to a type of beauty contest where each observer's assessment is defined by that of her counterparts). Two distinct, but related, effects of financial crises are grounded in nonrational "herd" behavior, by which markets move up and down dramatically based on small movements irrationally mimicked by others. See Christopher Avery \& Peter Zemsky, Multidimensional Uncertainty and Herd Behavior in Financial Markets, 88 AM. ECON. REv. 724, 724 (1998); V.V. Chari \& Patrick J. Kehoe, Financial Crises as Herds: Overturning the Critiques, 119 J. ECoN. THEORY 128, 129-30 (2004); cf. Paul Krugman, A Model of Balance-of-Payment Crises, 11 J. MONEY CREDIT \& BANKING 311, 319 (1979) (noting that balanceof-payments crises tend to occur when "speculators" as a group act in response to a belief that the government is about to abandon its fixed exchange rate). Whether it is the rational dynamic of strategic complementarity or irrational patterns of herd behavior, both accounts rest on a dynamic in which market returns depend on the coordination of investors around one equilibrium or another.

39. Maurice Obstfeld, by way of example, has modeled currency crises as exhibiting bank-run-style multiple equilibria, in which speculators do or do not attack a currency, depending on their expectations of other speculators' likely behavior. See Maurice Obstfeld, Models of Currency Crises with SelfFulfilling Features, 40 EUR. ECON. REV. 1037, 1039 (1996).

40. Other accounts of coordination in the financial markets might also be offered. Hayek's theory of the function of price is a story of economic coordination. See FRIEDRICH A. HAYEK, THE CONSTITUTION OF LIBERTY 227-30 (1960) (discussing how price is dependent upon several factors working together). The Austrian school's account of money is likewise an account of coordination at its foundation. See Murray N. Rothbard, THE LOGIC OF ACTION I: METHOD, MONEY, AND THE AUSTRIAN SCHOOL 211-12 (1997). The effective valuation of money thus necessitates some dynamic of coordination. More concrete dynamics of coordination might be seen in the creation and the evolution of financial market infrastructure. See Ahdieh, supra note 38, at 223-29. Recent debates over the wave of linkages among exchanges and securities trading systems, as well as some incidents of full-fledged merger, can be understood in this light. See, e.g., Ioannis Kokkoris \& Rodrigo Olivares-Caminal, Lessons from the Recent Stock Exchange Merger Activity, 4 J. COMPETITION L. \& ECON. 837, 855 (2008) (discussing the issues of competition-concern and coordination-related matters). The same is true of discussions over the growing practice of the duallisting of stocks on multiple exchanges. See Dana T. Ackerley II \& Eric J. Pan, 
The financial markets, meanwhile, are far from unique in the centrality of coordination to their operation. To the contrary, the strongest evidence of the growing importance of coordination in modern social and economic life may be in other areas. Consider the ever-increasing influence of the Internet.

The Internet, like the financial markets, is a massive exercise in coordination. Its operation-with its dependence on common standards for file sharing, interoperable search tools, and an effective network for interconnection-involves coordination at every level.41 Faced with an array of alternative file transfer protocols, for example, the emergence of the Internet required regulators to embrace a common standard. 42 Thus, we see an important role for the Internet Engineering Task Force (IETF) in coordinating users around that and other standards. No less significant has been the ongoing role of the IETF in facilitating the evolution of Internet protocols and standards. 43

Coordination likewise undergirds, if in distinct ways, the Internet backbone: the über-network of trunk lines by which

Dual-Listing Securities in Europe and the United States, in THE COMPLETE GUIDE TO LISTING ON THE LONDON STOCK EXCHANGE 7 (2002) ("The coordination between the U.S. and the non-U.S. tranches of the offering must be carefully worked out ...."). Even the heated response to the Securities and Exchange Commission's moves toward harmonization of disclosure standards might be seen to implicate the coordination dynamic at work in the securities market structure. See Patrick E. Hopkins et al., Response to the SEC Release: Acceptance from Foreign Private Issuers of Financial Statements Prepared in Accordance with International Financial Reporting Standards Without Reconciliation to U.S. GAAP File No. S7-13-07, 22 ACCT. HORIZONS 223, 223-33 (2008) (critiquing the SEC's proposal to accept financial statements from foreign private issuers prepared in accordance with International Financial Reporting Standards (IFRS), without reconciling such statements with U.S. GAAP).

41. See generally Sharon Eisner Gillett \& Mitchell Kapor, The SelfGoverning Internet: Coordination by Design, in COORDINATION OF THE INTERNET 3 (Brian Kahin \& James Keller eds., 1997), available at http://ces .mit.edu/papers/CCSWP197/CCSWP197.html.

42. See id. at 11 (stating that protocol standards must be agreed upon if they are to be operable).

43. See id. at 12-13 (describing IETF's role in developing Internet protocols and standardizing existing practices, particularly as to interoperability questions). The IETF's ongoing coordinative role might be usefully contrasted with the episodic pattern of regulatory coordination commonly at work in the financial markets. In the latter case, a coordination role for regulation becomes especially critical when the market shifts to the suboptimal equilibrium of diminished lending and investment. See supra notes 32-37 and accompanying text. In many coordination settings, however, from the Internet to the encouragement of innovation, the coordination role of regulation is more likely to be ongoing. 
local access networks are connected with one another. ${ }^{44}$ In recent years, the construction, expansion, and control of the backbone has provoked heated debates, behind which stand questions of coordination. ${ }^{45}$ Most fundamentally, the very nature of the Internet is a dynamic of coordination. It relies on a noncentralized system of data processing that occurs at network endpoints rather than within the network itself. ${ }^{46}$ Such a system is inherently one of coordination. ${ }^{47}$

The coordination dynamic underlying the Internet suggests yet other dimensions of our social and economic life that are grounded in coordination. It highlights, for example, the increasing importance of standard-setting issues in modern industrialized nations. ${ }^{48}$ In many of the most important areas of technological innovation today, interoperability is the key characteristic of relevant technologies. ${ }^{49}$ The benefits of highdefinition television (HDTV), for example, depend on the compatibility of HDTV television units, data distribution networks, and relevant programming. ${ }^{50}$ Developments in wireless communications are to similar effect. ${ }^{51}$ The importance of standardized technologies can also be seen in the increasing inci-

44. See Kevin Werbach, The Centripetal Network: How the Internet Holds Itself Together, and the Forces Tearing It Apart, 42 U.C. DAVIS L. REV. 343, $346 \mathrm{n} .11$ (2008) ("Backbones are the Internet's long-distance links between local access networks.").

45. See generally id. (discussing the centralization/decentralization debate surrounding the Internet backbone). Operation of the Internet thus depends on coordination across an array of data networks and core routers, and hence among the various governmental, commercial, and academic institutions that own or control those systems. See Judith A. Endejan, Cable's "Other Hat"Providing Telecommunications Services, in CABLE TELEVISION LAW 1999, at 291, 339-47 (PLI Patents, Copyrights, Trademarks, \& Literary Prop., Course Handbook Ser. No. G0-0003A, 1999).

46. See Werbach, supra note 44 , at 399-400.

47. See id. at $345-46$.

48. The growing influence of the International Organization for Standardization (ISO) helps to highlight as much. See INT'L ORG. FOR STANDARDIZATION, ISO IN BRIEF 2-3 (2008), available at http://www.iso.org/iso/ isoinbrief_2008.pdf.

49. See Saul Hansell, Connecting Gadgets Is Theme at Annual Show, N.Y. TIMES, Jan. 7, 2009, at B7, available at 2009 WLNR 349655.

50. See Joel Johnson, HDTV Guidebook, POPULAR MECHANICS, Jan. 2006, at $32,32-34$.

51. Cf. T.G. Zimmerman, Wireless Networked Digital Devices: A New Paradigm for Computing and Communication, 38 IBM SYSTEMS J. 566, 571-73 (1999), available at http://ieeexplore.iee.org/stamp/stamp.jsp?tp=\&arnumber= $5387057 \& \operatorname{tag}=1$ (discussing the ability of wireless technologies to share information). 
dence of standards conflicts in recent years, including the extended battle between Blu-ray and HD DVD standards, ${ }^{52}$ the International Organization for Standardization's controversial adoption of Microsoft's Open Office XML standard,53 and the geopolitical tensions surrounding China's development of its own wireless services standard.54 Standard setting is also critical outside the technological sphere, playing a role in disclosure standards in various settings (including the financial markets), ${ }^{55}$ environmental protection standards, ${ }^{56}$ and data collection and compilation initiatives in any number of areas. ${ }^{57}$ In these and other standard-setting pursuits, the critical issue is again effective coordination. The very point of a standard is to serve as a means of coordination-as a way to get everyone on the same page.

The network dimensions of the Internet, meanwhile, highlight the growing universe of network industries as settings in which coordination is essential. Most tangibly, one might cite recent discussions of high-speed rail networks and a modernized power transmission grid, 58 particularly following the February 2009 stimulus bill's provision of federal seed money for

52. See Laura Evans, Monitoring Technology in the American Workplace: Would Adopting English Privacy Standards Better Balance Employee Privacy and Productivity?, 95 CALIF. L. REV. 1115, 1148 n.242 (2007) (noting the extended standards battle between Blu-ray and HD DVD standards).

53. See Peter Sayer, ISO Confirms Approval of OOXML, Gives Two Months to Appeal, COMPUTERWORLD (Apr. 2, 2008), http://www.computerworld.com/ s/article/print/9074358/ISO_confirms_approval_of_OOXML_gives_two_months_ to_appeal?taxonomy Name=Security\&taxonomyId $=1$.

54. See Christopher S. Gibson, Globalization and the Technology Standards Game: Balancing Concerns of Protectionism and Intellectual Property in International Standards, 22 BERKELEY TECH. L.J. 1403, 1404-05 (2007).

55. See Troy A. Paredes, A Systems Approach to Corporate Governance Reform: Why Importing U.S. Corporate Law Isn't the Answer, 45 WM. \& MARY L. REV. 1055, 1097 (2004).

56. See, e.g., Daniel A. Farber, Revitalizing Regulation, 91 MICH. L. REV. 1278, 1290-93 (1993).

57. Data collected by the U.S. Census Bureau on public school finances is suggestive. See Preston C. Green, III et al., Achieving Racial Equal Educational Opportunity Through School Finance Litigation, 4 STAN. J. C.R. \& C.L. 283, 302 n. 130 (2008).

58. See Matthew L. Wald, Wind Energy Bumps into Power Grid's Limits, N.Y. TIMES, Aug. 27, 2008, at A1, available at 2008 WLNA 16147962; Matthew Daly, Stimulus Bill Would Boost NW Grid, Wind Energy, SEATTLE TIMES, Feb. 1, 2009, http://seattletimes.nwsource.com/html/localnews/2008695421 apstimulusbpa.html. 
these projects. ${ }^{59}$ In the construction of these network structures, as in the less bricks-and-mortar development of the Internet backbone and the growing linkages among securities trading systems, coordination constitutes the relevant goal. Coordination can likewise be seen in the development and evolution of the very different network forms exemplified by Facebook, Twitter, and other online social networks. 60

Finally, the centrality of innovation to the Internet helps to suggest the importance of coordination for innovation generally. In part, this can be traced to present-day structures of innovation finance. ${ }^{61}$ More significantly, it rests on the explosion of patenting in recent decades and the resulting need for innovators to coordinate their efforts with a wide and diverse array of patent holders. ${ }^{62}$ Much of the slowing pace of innovation in recent years can consequently be traced to failures of coordination.

Coordination therefore stands at the center of a great deal of what we think about, and worry about, in the modern social and economic order. In the construction of physical networks, such as the electrical grid, this is readily apparent. In the prevention and alleviation of financial crises and the facilitation of efficient levels of technological innovation, by contrast, it lies beneath the surface. Coordination plays a narrow and defined role in some settings, but is pervasive in others. Whatever its visibility or scope in any given setting, it is clear that the place of coordination in the social and economic order warrants our attention.

59. See Daly, supra note 58; David M. Herszenhorn, Even After the Deal, Tinkering Goes On, N.Y. TIMES, Feb. 13, 2009, at A20, available at 2009 WLNR 2851263.

60. See Nicole B. Ellison et al., Social Network Sites and Society: Current Trends and Future Possibilities, INTERACTIONS, Jan.-Feb. 2009, at 6, 6.

61. See Curtis J. Milhaupt, The Market for Innovation in the United States and Japan: Venture Capital and the Comparative Corporate Governance Debate, 91 NW. U. L. REV. 865, 865-67 (1997).

62. See MichaEl Heller, The Gridlock ECONOMY: How TOO MuCH OWNERSHIP WRECKS MARKETS, STOPS INNOVATION, AND COSTS LIVES 6 (2008) (arguing that patent laws for medical research reduce collaboration and block the development of potentially helpful drugs and yet no one complains); $\mathrm{Mi}$ chael A. Heller \& Rebecca S. Eisenberg, Can Patents Deter Innovation? The Anticommons in Biomedical Research, 280 SCIENCE 698, 698-701 (1998); Robert E. Thomas, Debugging Software Patents: Increasing Innovation and Reducing Uncertainty in the Judicial Reform of Software Patent Law, 25 SANTA ClARA COMPUTER \& HIGH TECH. L.J. 191, 213 (2008) (describing "patent thickets" in computer software development); infra notes 74-75 and accompanying text. 
Why, then, has coordination not been a subject of close study by legal scholars? At least in part, it is because our current frame of mind has rendered coordination invisible to us. ${ }^{63}$ Coordination has largely been seen as the responsibility of the market. ${ }^{64}$ Where coordination materializes in one form versus another, or fails to emerge at all, we see no coordination failure. Rather, as determined pupils of Adam Smith's Wealth of $\mathrm{Na}$ tions, ${ }^{65}$ we instead see an invisible hand having dictated that a particular coordination point-or no coordination at all-was the optimal result. When it comes to coordination, there has consequently been little to discuss.

Of late, however, a number of scholars have begun to engage the dynamics of coordination. ${ }^{66}$ For the most part, they have not explicitly acknowledged, or perhaps even appreciated, as much. Yet their work has highlighted the centrality of visible, active, and conscious coordination in modern social and economic life. ${ }^{67}$ Although writing on divergent subjects, and offering distinct conclusions, all can be seen to be engaged with stories of coordination and the myriad ways in which it changes things. ${ }^{68}$

Consider The Gridlock Economy: How Too Much Ownership Wrecks Markets, Stops Innovation, and Costs Lives, in which Michael Heller explores the potential for a "tragedy of the anticommons" in property law. ${ }^{69}$ As framed by Heller, the dynamic is the inverse of the familiar tragedy of the commons, in which a lack of private property rights fosters overconsumption. ${ }^{70}$ In the tragedy of the anticommons, we see just the opposite: a dynamic in which excess property rights foster underuse of relevant resources. ${ }^{11}$ Because of ambiguity in iden-

63. $C f$. HELLER, supra note 62 , at 23 (explaining the difficulty in fixing problems without first creating a consensus on certain aspects of the problems).

64. More precisely, it is the price function that is ordinarily understood as the mechanism of efficient coordination in a market economy. See GEORGE J. STIGLER, THE THEORY OF PRICE 85 (3d ed. 1966).

65. SMITH, supra note 10.

66. See, e.g., HELLER, supra note 62, at 6.

67. See id.

68. The authors thus variously suggest a need to reassess the place of the market incentives and the role of the individual, to reconsider the potential impact of spontaneous action and the nature of production, and to recognize the increasing role of knowledge and information in the generation of wealth. See infra notes 60-80 and accompanying text.

69. HELLER, supra note 62, at 18.

70. See id. at $18-19$.

71. See id. 
tifying pertinent ownership rights, transaction costs in securing the authorization of all relevant rights holders, and other difficulties attendant to a multiplicity of ownership, resources end up sitting idle. ${ }^{72}$

Such excess ownership and resulting tragedies of the anticommons, Heller suggests, are common in modern industrial economies. ${ }^{73}$ Perhaps most dramatically, he highlights the relatively slow pace of innovation in pharmaceutical products-a striking state of affairs, given the great expectations for the biotech revolution in its early days. ${ }^{74}$ This result proves unsurprising, though, when we recall the dispersion of patent rights among a broad and sometimes difficult to identify class of rights holders. Caught between the high costs of trying to coordinate this group and the risk of costly litigation should the group inadvertently exclude any member, potential innovators instead abandon their efforts. ${ }^{75}$

This pattern in pharmaceutical innovation is far from unique. Heller likewise highlights other settings in which dispersed ownership has generated underuse of a valuable resource. ${ }^{76}$ Air travel delays would be readily alleviated, he suggests, were we to construct a few additional runways across the United States. ${ }^{77}$ Given the fragmented ownership of relevant land and the absence of any ready mechanism for its assembly, however, those runways remain unbuilt. Similarly, fragmented licensing of the telecommunications spectrum by the Federal Communications Commission has left wide swaths of the spectrum unused, which has caused the United States to lag well behind Japan and South Korea in wireless broadband penetration. ${ }^{78}$ Efficient power transmission and potential new forms of artistic creativity, Heller suggests, are yet further victims of the tragedy of the anticommons. 79

The fatal flaw in these settings is not suboptimal action by individual owners. Rather, it is the inaction by owners collectively that has resulted in the market failure. The operative challenge is to coordinate property-rights holders around an ef-

72. See id.

73. See id. at 19-20.

74. See id. at $49-50$.

75. See id. at $49-52$.

76. See id. at 19-20.

77. See id. at 8-9.

78. See id. at 81 .

79. See id. at 13-16, 19-20. 
ficient equilibrium of consumption and use. As in the financial markets and the Internet, the essential need in pharmaceutical innovation, airport construction, and telecommunications is to capitalize on an underutilized resource. ${ }^{80}$ This requires effective coordination of dispersed owners, whether amidst a dense thicket of patents, among divided property interests, or across a fragmented broadcast spectrum. ${ }^{81}$ Where this need for coordination is unmet, productive assets will go to waste. ${ }^{82}$ Further aggravating the relevant tragedy, such underuse will often go unnoticed: How do we know that something that might have been created or developed was not? How do we recognize a failure of coordination?

Yochai Benkler, in his The Wealth of Networks: How Social Production Transforms Markets and Freedom, ${ }^{83}$ might be seen to offer the flip side of Heller's story. In his account, dispersed ownership likewise plays a leading role, not in encouraging underuse, but in changing the nature of mass production. Benkler's account thus highlights the rise of what he terms "peer production." 84

In Benkler's story, two phenomena have created a "networked information economy": first, the increasing importance of information, cultural production, and the manipulation of symbols (or branding) in the global economy; and second, the network structure of the Internet, in which processing power is distributed rather than concentrated. ${ }^{85}$ Within this economy, in turn, we can observe three shifts from traditional modes of economic production. First, nonproprietary, even nonmarket, strategies become viable, given the distinct characteristics of information and cultural production. ${ }^{86}$ Second, such nonmarket production can exert an impact far beyond what it could have achieved in the past, given the potentially infinite reach of the Internet. ${ }^{87}$ Finally, at the intersection of these two, there emerges the possibility of peer production, whereby large-scale coordinated efforts generate information, knowledge, and cul-

80. See id. at 2 .

81. For an amusing example, see $i d$. at $6-7$.

82. See id. at 2.

83. Yochai BENkLeR, The Wealth OF NETWORKS: HOW SOcIal PRODUCTION TRANSFORMS MARKETS AND FREEDOM (2006).

84. See id. at 62 .

85. See id. at 3.

86. See id. at 105-06.

87. See id. 
ture. ${ }^{88}$ Rather than production within the hierarchical firm or through arms-length transactions on the market, such production engages untold millions of otherwise unaffiliated producers in the coordinated development of information goods. ${ }^{89}$

Most familiar among Benkler's examples is Wikipedia, within the framework of which a mass of dispersed, loosely organized Internet users have effectively coordinated inputs of information, knowledge, and time. ${ }^{90}$ The result is a free, readily accessible information resource with accuracy levels roughly comparable to traditional information resources such as the Encyclopedia Britannica. ${ }^{91}$ Only slightly less familiar an example may be the open source Linux operating system, use of which has exploded over the last decade..$^{92}$ Developed and constantly improved through the coordinated efforts of otherwise unaffiliated software developers around the world, Linux is freely available for individual and institutional use under an open public license. ${ }^{93}$ Other examples of peer production can also be identified, including social networks such as Facebook, Twitter, and the Flickr network for photo distribution. ${ }^{94}$

Beyond the analysis of Heller and Benkler, the work of other authors is also suggestive of a growing appreciation of the dynamics of coordination. Consider Larry Lessig's Remix: Making Art and Commerce Thrive in the Hybrid Economy, his latest challenge to our conventional thinking about copyright regulation. ${ }^{95}$ In Remix, Lessig highlights the growing emergence of a "Read-Write" (RW) culture alongside the prevailing "Read Only" (RO) culture. ${ }^{96}$ In the former, by contrast with the latter, consumers no longer simply sit back and take in the informa-

88. See id.

89. See id.

90. See id. at 70-74.

91. See Jim Giles, Internet Encyclopedias Go Head to Head: Jimmy Wales' Wikipedia Comes Close to Brittanica in Terms of the Accuracy of its Science Entries, a Nature Investigation Finds, NATURE, Dec. 15, 2005, at 900, 900-01.

92. See generally H. Maura Lendon, The Linux Revolution, 15 INTELL. PROP. J. 143, 148, 156-57 (2000) (noting that the development of Linux as Open Source software was intended to take advantage of "hundreds of users providing feedback, suggestions for improvement and new code to fix bugs and enhance the program," and to use "continual "peer review" to improve its quality).

93. GNU General Public License: Version 2, LINUX ONLINE (June 1991), http://www.linux.org/info/gnu.html [hereinafter LINUX].

94. See generally FACEBOOK (2010), http://www.facebook.com/; FLICKR (2010), http://www.flickr.com/; TwITTER (2010), http://twitter.com/.

95. See LESSIG, supra note 3, at 18-19.

96. See id. at $28-35$. 
tional, intellectual, and cultural goods they purchase. Rather, through existing and ever-advancing digital technologies, they actively engage in shaping and recreating those goods. ${ }^{97}$ Instead of a marketplace in which millions consume the products of a handful of producers - think here of broadcast television or analog music production and distribution-today everyone is a producer, a distributor, and a consumer.98 To similar effect is Clay Shirky's Here Comes Everybody: The Power of Organizing Without Organizations. ${ }^{99}$ Offering an even broader vision of coordinated action in the modern social and economic order, Shirky highlights the growing range of opportunities for joint, yet decentralized, action and initiative, and the impact of this pattern on social, economic, and even political life. ${ }^{100}$ Finally, even aspects of Richard Thaler and Cass Sunstein's Nudge: Improving Decisions About Health, Wealth, and Happiness can be understood within a framework of coordination. ${ }^{101}$ Based on the findings of behavioral economics and psychology, they counsel the use of noncoercive, information-oriented "nudges" to shape individual choice-interventions that echo those favored by the emphasis on coordination I propose. 102

In each of these works, as in the analyses of Heller and Benkler, coordination is central to the story told. 103 The insight offered by each author turns on the importance of coordination in the social and economic order. Conflict may well be present in the settings explored. It is not, however, at the heart of the motivations, incentives, and interactions we observe. Rather,

97. See id. at 28.

98. A further dimension of coordination might be seen in Lessig's arguments about the ways in which the economics of business is changing, including through technologies that rely on freely contributed consumer data to generate value. Think here of Google's PageRank system, and of Amazon.com's and Netflix's use of customer purchases (and page views) to improve the quality of their recommendations. See id. at 122-28.

99. Clay SHIRKY, HERE COMES EvERYBODY: THE POWER OF ORGANIZING WITHOUT ORGANIZATIONS (2008).

100. Id. Shirky describes, for example, the striking use of so-called flash mobs in antigovernment protests in Belarus. See id. at 166-71. Using text messaging and weblogs, such protests are quickly brought together, with little or no advance planning. In this way, they permit protest, while allowing organizers to more easily avoid detection. See $i d$.

101. RICHARD H. THALER \& CASS R. SUNSTEIN, NUDGE: IMPROVING DECISIONS ABOUT HEALTH, WEALTH, AND HAPPINESS (2008).

102. See id. at 4-6.

103. See generally BENKLER, supra note 83 (describing the important of coordination); HELLER, supra note 62 (same); LESSIG, supra note 3 (same); SHIRKY, supra note 99 (same). 
the operative challenge and the desired goal in these settings is to get people on the same page. They are stories of coordination.

None of the authors explicitly acknowledge as much. More importantly, they do not engage with the coordination dynamic at work. Writing variously on property rights, Internet law, copyright, and other topics, they tend not to see themselves as writing on a common theme. ${ }^{104}$ This only further highlights the need to bring the dynamics of coordination in the modern social and economic order to the foreground of our analysis and to more fully engage with its consequences. In particular, it is essential that we consider the implications of the coordination economy for the function and role of the modern regulatory state.

\section{DEFECTION, COORDINATION, AND THE REGULATORY STATE}

From its varied manifestations in the financial markets, the Internet, and elsewhere, to its growing role in the scholarly literature, coordination emerges as a crucial dimension of modern social and economic life. But what is the significance of the rise of the coordination economy for law as opposed to economics or sociology? More specifically, what are its implications for the regulatory state?

It is interesting, in this vein, to consider the place of law in the analysis of Heller, Benkler, Lessig, and other scholars who have begun to engage dynamics of coordination in the social and economic order. For the most part, law is absent. Where it does appear, it is most often cast as an obstacle to the desired result. ${ }^{105}$ In the pursuit of coordination, law and regulation emerge as something to be avoided or overcome.

This should not be especially surprising, as it follows naturally from our conventional thinking about both coordination and regulation. As suggested above, we begin with a sense of coordination as the particular responsibility of the market. In a market economy, the source of coordination is the price func-

104. My point is not that these accounts all collapse into the same story; nor do I suggest that coordination explains everything that the authors observe. Rather, I simply suggest that each of the works' divergent subjects and distinct conclusions have at their hearts a dynamic of coordination, which surely implies something.

105. See, e.g., LINUX, supra note 93 (describing the "threat" posed by software patents). 
tion. ${ }^{106}$ Regulation, conversely, has not commonly been seen as a vehicle for coordination. 107 Our thinking on each count turns out to be wrong.

To appreciate as much, as well as the implications of the coordination economy for the regulatory state, game theory offers helpful insight. To be sure, as its detractors suggest, it is not fully determinate. There is far too much ambiguity in the definition of real-world payoffs to ground positive claims on game theory alone. ${ }^{108}$ Game theory constitutes a useful frame of analysis, however, so long as we do not inhale.

In this spirit, the following discussion begins by highlighting the common foundation of many of our traditional arguments for regulatory intervention - externalities, the tragedy of the commons, and other collective action problems - in the fear of defection emphasized by the famous Prisoner's Dilemma. Suggesting the limited relevance of this framework to coordination settings, I then offer the distinct construct of coordination games as a frame for analysis. Although less familiar to legal scholars, coordination games are no less relevant to the study of law and provide a more suitable approach to the areas of interest herein. Finally, I conclude this part by identifying the distinct catalysts for regulatory intervention in settings defined by coordination versus defection and dismissing potential challenges to the need for regulation in coordination settings.

106. The important caveat to this lies in theories of the firm. See Edward B. Rock \& Michael L. Wachter, Islands of Conscious Power: Law, Norms, and the Self-Governing Corporation, 149 U. PA. L. REV. 1619, 1621-22 (2001). See generally R.H. Coase, The Nature of the Firm, 4 ECONOMICA 386, 386 (1937). The firm constitutes a counterpoint to market-based coordination by way of price. Cf. CHANDLER, supra note 11 , at 490 .

107. To be sure, some have recognized as much. I have already noted the work of Richard McAdams. See supra note 18. In After the Rights Revolution, Sunstein highlights the role of regulation in responding not only to collective action problems, but to coordination problems as well. See CASS R. SUNSTEIN, AFTER THE RIGHTS REVOLUTION: RECONCEIVING THE REGULATORY STATE 5152 (1990). Notably, though, he places relatively little emphasis on the latter functions. Further, he continues to emphasize the coercive role of regulation in those settings. Compare id. ("[C]oercion has an often overlooked facilitative function."), with infra Part III.A.1 (highlighting the role of regulation in shaping expectations rather than incentives).

108. See Douglas G. BaIRd e'T Al., Game Theory AND the LaW 45, 62 (1994); JÜRGEN EICHBERGER, GAME THEORY FOR ECONOMISTS 1 (1993) (noting the reliance of game theory on rational players). From the opposite direction, I fully appreciate the relative simplicity of the $2 \times 2$ games on which I rely. For the purposes intended herein, however, a bracketing of additional players, mixed strategies, sequential versus simultaneous plays, and evolutionary patterns may actually be most effective. See McAdams, supra note 18, at 211. 


\section{A. The Dilemma of Defection and the Regulatory State}

As Richard McAdams has recently highlighted, legal scholars' use of game theory has focused almost exclusively on the well-known Prisoner's Dilemma. ${ }^{109}$ In this familiar dynamic, each co-conspirator to a crime must decide whether to confess, given the threat of a far more severe sentence if she remains silent while her counterpart confesses, and the promise of a free pass if she alone chooses to sing like a bird. In such circumstances, the Prisoner's Dilemma predicts that both prisoners will end up confessing, even though they would have been better off had they both held their tongues and refused to provide the prosecution with the evidence necessary for a conviction. ${ }^{110}$

The dispositive characteristic of the Prisoner's Dilemma, then, is a dynamic of defection. ${ }^{111}$ Although both social and private utility are maximized if the players remain silent, their individual incentives lead them to defect from that optimal equilibrium and both end up worse off. The solution to the Prisoner's Dilemma, in turn, lies in altering players' payoffs and thereby eliminating their incentive to defect. 112

In substantial part, our notions of regulation can be understood to turn on just such a vision of defection.113 Public goods, collective action, negative externality, and other familiar justifications for regulatory intervention are Prisoner's Dilemmas at heart. ${ }^{114}$ Behind each argument is the fear that individ-

109. See McAdams, supra note 18 , at 214-15.

110. See ROGER B. MYERSON, GAME THEORY: ANALYSIS OF CONFLICT 97 (1991) (introducing the Prisoner's Dilemma). For a more complete analysis, See AVINASH DiXIT \& SUSAN SKEATH, GAMES OF STRATEGY 256-57 (1999).

111. See Susan Block-Lieb, Congress' Temptation to Defect: A Political and Economic Theory of Legislative Resolutions to Financial Common Pool Problems, 39 ARIZ. L. REV. 801, 813 (1997); cf. Ronald J. Gilson \& Robert H. Mnookin, Disputing Through Agents: Cooperation and Conflict Between Lawyers in Litigation, 94 COLUM. L. REV. 509, 514-18 (1994) (discussing defection within a Prisoner's Dilemma in the context of litigation).

112. See, e.g., Block-Lieb, supra note 111, at 818-19.

113. See, e.g., Gideon Doron, Administrative Regulation of an Industry: The Cigarette Case, 39 PUB. ADMIN. REV. 163, 165-67 (1979) (describing regulation of defection in oligopolist cigarette advertising); see also Kent Greenfield, Using Behavioral Economics to Show the Power and Efficiency of Corporate Law as Regulatory Tool, 35 U.C. DAVIS L. REV. 581, 599 (2002) (noting the necessity of regulation to prevent defection-based market failures).

114. See, e.g., ROBERT O. KEOHANE, AFTER HEGEMONY: COLLABORATION AND DISCORD IN THE WORLD POLITICAL ECONOMY 67-69 (1984); John K. Setear, An Iterative Perspective on Treaties: A Synthesis of International Relations Theory and International Law, 37 HARV. INT'L L.J. 139, 178 n.160 (1996). 
uals and institutions will sometimes be incentivized to defect from optimal social arrangements and choices. The task of the regulatory state is to alter relevant payoffs and thereby prevent such defection. ${ }^{115}$

Consider public goods arguments for regulation. In public goods settings, we find a resource that is a "common or collective benefit[] provided by government[]" regardless of one's individual contribution to it. ${ }^{116}$ It is impossible, or at least difficult, to bar its use by additional consumers. Such use, on the other hand, does not preclude consumption by others. ${ }^{117}$ In such settings, individuals can be expected to free ride on the demand of others, consuming more than they are willing to contribute toward the relevant resource.

This, of course, is precisely the dynamic of defection predicted by the Prisoner's Dilemma. ${ }^{118}$ If all contribute their share toward production of the relevant public good-be it police protection, public roadways, national defense, scientific research, or the proverbial lighthouse-social and private utility are maximized. The incentive of individuals and institutions to free ride by understating their demand for public goods, however, generates the opposite result. Writ large, such incentives dictate little or no production of public goods with concomitant losses to both social and private utility. ${ }^{119}$

This is likewise the dynamic in the tragedy of the commons, famously described by Garrett Hardin with reference to cattle grazing on a common plot. ${ }^{120}$ The tragedy arises because

115. See Doron, supra note 113, at 167; Greenfield, supra note 113, at 599; cf. Eyal Zamir, The Efficiency of Paternalism, 84 VA. L. REV. 229, 248-52 (1998) (arguing that "systematic deviations from the rational-maximizer model" undermine the position of principled antipaternalism).

116. See Mancur Olson, JR., The Logic of Collective ACtion 14 n.21, $14-15$ (1971).

117. Id.

118. See David W. Leebron, Games Corporations Play: A Theory of Tender Offers, 61 N.Y.U. L. REV. 153, 188-90 (1986) (describing the tender offer problem in terms of free riders and the Prisoner's Dilemma); McAdams, supra note 18, at 215 n.24; David Schmidtz, Contracts and Public Goods, 10 HARV. J.L. \& PUB. POL'Y 475, 479-83 (1987).

119. Free-rider dynamics generally have similar effects. See Schmidtz, supra note 118 , at $475-82$.

120. See Garrett Hardin, The Tragedy of the Commons, 162 SCIENCE 1243, 1244 (1968). Hanoch Dagan and Michael Heller describe commons property as "the axiomatic example of a prisoner's dilemma." Hanoch Dagan \& Michael A. Heller, The Liberal Commons, 110 YALE L.J. 549, 555 (2001); see also THOMAS C. SCHELLING, MiCROMOTIVES AND MACROBEHAVIOR 110-15 (1978) (describing the tragedy of the commons as a Prisoner's Dilemma); Lee Anne Fennell, 
each herder is incentivized to maximize their individual gain by having as many cattle on the pasture as possible. ${ }^{121}$ The result, however, is over grazing. ${ }^{122}$ Similar tragedies might arise from residents' use of a public park or the use of a local watershed for waste disposal. In each of these cases, individual defection from an optimal equilibrium of constrained consumption produces a net social and private loss. As Hardin eloquently put it, "[r]uin is the destination toward which all men rush, each pursuing his own best interest in a society that believes in the freedom of the commons." 123

Broadly, in fact, the entire universe of collective action failures-public goods problems, tragedies of the commons, and free riding, among other arguments for regulatory intervention-can be understood as stories of defection. ${ }^{124}$ As highlighted by Mancur Olson, collective action problems arise from the limited return to any given individual of addressing a social dilemma. ${ }^{125}$ Climate change regulation may be the timeliest example. Notwithstanding the collective utility of adjustment in this setting, individuals may seek to free ride, producing a net reduction in both social and private utility. ${ }^{126}$ Once again, individual defection -in this case, the failure to lend support to a common project-constitutes the critical impetus for regulation.

Our most basic arguments for regulatory intervention, then, arise out of a particular vision of the social and economic order. An emphasis on collective action problems, as well as negative externalities, markets for lemons, and information

Common Interest Tragedies, 98 Nw. U. L. REv. 907, 944 (2004); Robert W. Hillman, Business Partners as Fiduciaries: Reflections on the Limits of Doctrine, 22 CARDOZo L. REV. 51, 74 n.65 (2000); Anatol Rapoport, Prisoner's Dilemma, in The New PalgRave: GAME Theory 199, 204 (John Eatwell et al. eds., 1989) (noting that the Prisoner's Dilemma becomes a version of the so-called tragedy of the commons when generalized to more than two participants).

121. See Hardin, supra note 120, at 1244.

122. Id.

123. Id.

124. See, e.g., Lisa Schenck, Climate Change "Crisis"-Struggling for Worldwide Collective Action, COLO. J. INT’L ENVTL. L. \& POL'Y 319, 335 (2008) (discussing climate change as a defection problem); see also Leebron, supra note 118, at 188-90 (describing defection in the context of tender offers); Schmidtz, supra note 118, at 479-83 (considering defection from investment in informational public goods); $c f$. Block-Lieb, supra note 111, at 810-20 (discussing defection in common pool problems).

125. Cf. OLSON, supra note 116, at 2 ("[R]ational, self-interested individuals will not act to achieve their common or group interests.").

126. See Schenck, supra note 124, at 335-36. 
failures, among other market failures, speaks to a world in which the incentives of individuals and institutions will sometimes-if not often-motivate them to deviate from optimal equilibria. ${ }^{127}$ The prevention of such defection emerges as the key function of the regulatory state. ${ }^{128}$

\section{B. From DeFECTION TO COORDINATION}

A dynamic of defection is not the story at work in the coordination economy. In discouraging bank runs, encouraging bank lending, and otherwise fostering investment in the financial markets, defection is not the concern. If others are maintaining deposits, lending, and investing, there is limited individual incentive to deviate from that course. Few are incentivized to abandon the Internet or electrical grid to create their own network. The same might be said, if to a lesser degree, of the increasingly popular world of online social networks. If all my friends are on Facebook, I have little interest in moving to MySpace. The prospect of defection is likewise of limited relevance in standard setting, innovation, and the other coordination settings described above.

The important work of John Maynard Smith in evolutionary biology offers another vantage to appreciate as much. In Smith's account, the Prisoner's Dilemma can be reconceived as a "skulling game," in which a pair of rowers each hold a set of oars that extend out both sides of their boat. Here, we face our conventional worries of free riding and holdout problems, given

127. Individuals and institutions are motivated to deviate from optimal equilibria in circumstances cognizable as a Prisoner's Dilemma. See supra notes 111-15 and accompanying text. Negative externalities are similarly grounded in Prisoner's Dilemma stories of defection. See Fennell, supra note 120, at 944; Amir N. Licht, Games Commissions Play: $2 x 2$ Games of International Securities Regulation, 24 YALE J. INT'L L. 61, 88-89 (1999). Even patterns of information asymmetry and natural monopoly have been cast as species of Prisoner's Dilemmas. See, e.g., Robert S. Adler \& Elliot M. Silverstein, When David Meets Goliath: Dealing with Power Differentials in Negotiations, 5 HARV. NEGOT. L. REV. 1, 68 (2000) (describing a Prisoner's Dilemma dynamic in information disclosure); John Shepard Wiley Jr., Reciprocal Altruism as a Felony: Antitrust and the Prisoner's Dilemma, 86 MICH. L. REV. 1906, 1914-20 (1988) (analyzing cartels using the Prisoner's Dilemma); John Simpson \& Abraham L. Wickelgren, Bundled Discounts, Leverage Theory, and Downstream Competition, 9 AM. L. \& ECON. REV. 370, 370 (2007) (linking dynamics at work in monopoly settings to the Prisoner's Dilemma). "Market for lemons" problems are especially suitable to a Prisoner's Dilemma frame of analysis. See George A. Akerlof, The Market for "Lemons": Quality Uncertainty and the Market Mechanism, 84 Q.J. ECON. 488, 489 (1970).

128. See supra note 115 and accompanying text. 
the ability of each passenger to shirk their responsibility to row. ${ }^{129}$ By contrast is the only slightly-yet dramaticallymodified "rowing game," in which each rower holds only one oar, extending out opposite sides of the boat. With this minor modification, the payoffs to free riding or holding out suddenly disappear. Instead, we face the distinct challenge of coordinating behavior. ${ }^{130}$

An emphasis on the Prisoner's Dilemma and its dynamics of defection in framing the world faced by the regulatory state will therefore no longer suffice. A new account is necessary to accommodate the important, and increasingly widespread, manifestations of a coordination economy.

A distinct strand of game theory turns out to offer an alternative. This is the dynamic of coordination games. Here, as in the settings described above, the essential story is not one of defection, but of coordination.

Although unfamiliar to legal scholars in comparison with the Prisoner's Dilemma, the basic intuition behind coordination games turns out to be familiar. Perhaps most routinely, coordination-game dynamics have been highlighted in the choice of driving on the left or the right. ${ }^{131}$ Even in this basic setting, we can see the characteristic feature of a coordination game: the presence of multiple Nash equilibria. ${ }^{132}$ Whether both drive on the right or both drive on the left, the result will be stable. A driver will not abandon either the drive-on-the-right or the drive-on-the-left equilibrium, unless the other driver shifts as well. There is also the potential for catastrophic coordination failure, however, absent communication or relevant law or norms dictating where to drive.

Only slightly less familiar may be the so-called Meeting Place game. Here, players who have been separated from one another-whether friends in New York City, spouses in a department store, or otherwise-must find each other. ${ }^{133}$ Having failed to arrange a meeting place in advance and lacking the

129. See John MaYnaRD SMITH \& EÖRS SZathMÁRY, THE MaJOR TRANSITIONS IN EVOLUTION 261-62 (1995).

130. See id.

131. See, e.g., W. Bradley Wendel, Civil Obedience, 104 CoLUM. L. REV. 363,378 n.70 (2004).

132. See Vincent P. Crawford \& Hans Haller, Learning How to Cooperate: Optimal Play in Repeated Coordination Games, 58 ECONOMETRICA 571, 57172 (1990).

133. See THOMAS C. SCHELling, THE STRATEGY OF CONFLICT 54-56 (1960). 
ability to communicate, ${ }^{134}$ the dynamic that emerges is one of coordination. To locate one another, each must develop expectations of the likely behavior of the other. More precisely, they must develop an accurate expectation of what their counterpart will expect of them. ${ }^{135}$

Given the lack of conflict in this setting, this is a game of "pure coordination." 136 This is apparent in the normal form representation of the Meeting Place game, with its symmetric payoffs to both players. Both the player choosing along the vertical axis, whose payoff from each strategy is listed first, and the player choosing along the horizontal axis receive a payoff of five if they successfully locate one another. ${ }^{137}$

\begin{tabular}{|l|c|c|}
\hline & Penn Station & Grand Central \\
\hline Penn Station & $(5,5)$ & $(0,0)$ \\
\hline Grand Central & $(0,0)$ & $(5,5)$ \\
\hline
\end{tabular}

As with the choice between driving on the right or the left, we find multiple Nash equilibria here: meeting at Penn Station or at Grand Central Station. ${ }^{138}$ Each strategy is stable; neither player has any incentive to abandon a choice of location if they expect their counterpart to choose it. Efficient coordination consequently depends on each player developing an accurate expectation of whether their counterpart is likely to go to one station or to the other. To do so, the necessarily circular challenge for each is to determine where her counterpart will likely ex-

134. Thomas Schelling first described the Meeting Place game decades before invention of the mobile phone. Today, one might simply imagine having an iPhone in New York, but being unable to get a signal from AT\&T. See Mike Zapler, Wireless Data Logjam a Looming Crisis, SAN JOSE MERCURY NEWS, Feb. 7, 2010, at 1A, available at 2010 WLNR 2676654.

135. SCHELLING, supra note 133, at 54; see also Diamond \& Dybvig, supra note 31 , at 404 ("In contrast, a bank run in our model is caused by a shift in expectations ....").

136. See Judith Mehta et al., The Nature of Salience: An Experimental Investigation of Pure Coordination Games, 84 AM. ECON. REV. 658, 658 (1994).

137. Throughout this Article, I state the operative game payoffs as \{Row Player, Column Player\}, with Row Player's choices demarcated on the vertical axis and Column Player's choices on the horizontal axis.

138. Where relevant drivers have no preference between driving on the right or left side of the road, that choice is likewise captured by this set of payoffs. 
pect her to go, based upon where she expects the other to expect her to go, ad infinitum.

Assuming the above payoffs, this recursive exercise in expectation formation is necessary to avoid the coordination failure of going to different locations. The need for consistent expectations becomes even more acute where one coordination point is preferable to the other. A Pareto-ordering of relevant coordination equilibria thus introduces a further dimension of potential coordination failure.

Here, our friends continue to be separated in New York, but both are within blocks of Grand Central Station. We continue to have multiple Nash equilibria, as a meeting at either location would be a stable coordination point, from which neither would deviate or defect. Given their proximity to Grand Central Station, however, meeting there is a dramatically superior choice. ${ }^{139}$ Besides non-coordination, therefore, there exists a further possibility of coordination failure-meeting at the "wrong" place.

\begin{tabular}{|l|c|c|}
\hline & Penn Station & Grand Central \\
\hline Penn Station & $(3,3)$ & $(0,0)$ \\
\hline Grand Central & $(0,0)$ & $(6,6)$ \\
\hline
\end{tabular}

As in the coordination settings described above, the issue in these games is not defection. This remains true, as I will demonstrate below, even as we shift to more realistic coordination game settings where players' preferences conflict, sometimes dramatically. ${ }^{140}$ The irrelevance of defection, however, does not eliminate the potential for suboptimal results. Coordination games simply involve a distinct set of potential market failures.

A disconnect emerges, then, between the vision of the world on which traditional accounts of the regulatory state rely and the rise of the coordination economy. Conventional rationales for the regulatory state posit a world of Prisoner's Dilemmas, in which the state must intervene to alter individual and institutional incentives to defect from socially optimal equili-

139. Grand Central Station, of course, figured prominently in Schelling's experimental studies of coordination. See SCHELLING, supra note 133, at 55 n.1.

140. See infra Part II.C. 
bria. Critical aspects of modern social and economic life, however, are not effectively captured by this vision. Instead, these are stories of coordination.

In these settings, we do better to look to coordination games in seeking to understanding the dynamic at work. The point is not simply one of classification, however, or an abstract analytical exercise. In shifting from the Prisoner's Dilemma to coordination games, we arrive at a distinct vision of both the function and form of regulation. ${ }^{141}$ Where coordination is the operative demand on the regulatory state, the design of relevant regulation might be better keyed to that need. Our halting and muddled approach to the regulation of areas including the financial markets, the Internet, standard setting, and innovation, meanwhile, might be better explained by our inattention to the actual dynamics at work than any failure of regulation as such. ${ }^{142}$

\section{Dilemmas of CoORdination}

At first glance, the rise of the coordination economy might be seen as a manifesto for contraction of the regulatory state. Recall, once again, the notion of coordination as precisely the task that the market is designed to achieve. From that perspective, where coordination is the operative dynamic and defection is not a concern, regulatory intervention is unnecessary. Efforts at deregulation, the privatization of traditionally public functions, aspirations to end "big government," and an emphasis on

141. As I will describe below, see infra Part III.B.4, besides the coordination settings described in Part I, coordination-oriented regulatory approaches may also have application in those settings in which the Prisoner's Dilemma is played in indefinite repeat plays. In the latter circumstances, the Prisoner's Dilemma can essentially be understood to be transmuted into a coordination game. Cf. Peter Huber, Competition, Conglomerates, and the Evolution of Cooperation, 93 YALE L.J. 1147, 1151 (1984) (arguing that the marketplace setting differs from the classic formulation of the Prisoner's Dilemma because a firm can alter its strategic choice while it is being made in response to the behavior of other firms).

142. See, e.g., Robert W. Crandall \& J. Gregory Sidak, Is Structural Separation of Incumbent Local Exchange Carriers Necessary for Competition?, 19 YALE J. ON REG. 335, 339-40 (2002) (criticizing proposed telecommunications regulation as based upon the false premise that market failures are the result of anticompetitive behavior by incumbent local exchange carriers rather than a problem of integration and coordination); Schwarcz, supra note 29 , at $196-210$ (arguing that improper regulation of financial markets arises from a failure to understand the nature and sources of systemic risk). See generally Kesan \& Gallo, supra note 5, at 1502-05 (discussing the need to understand the operation of markets on the Internet in order to design effective Internet regulation). 
tax cuts might be justified by the heightened place of coordination in social and economic life. ${ }^{143}$

Legal scholars' single-minded orientation to the Prisoner's Dilemma is in accord with this view. ${ }^{144}$ Both positive and normative accounts of the regulatory state have emphasized the dynamic of the Prisoner's Dilemma, while disregarding coordination games. ${ }^{145}$ At least in part, this might be traced to an understanding of coordination along the above lines. Where coordination games capture the dynamic at work, the logic goes, law and regulation have little to add. Optimal coordination simply happens. ${ }^{146}$

But coordination failures turn out to be a real risk in settings including the financial markets, the encouragement of innovation, and standard setting. In any number of ways, coordination may not simply happen. As suggested above, this begins with the possibility of non-coordination. ${ }^{147}$ In this case, relevant actors enter a given market but fail to coordinate around a common equilibrium. ${ }^{148}$ The persistence of multiple standards in settings where harmonization might be preferable constitutes just such a coordination failure. ${ }^{149}$ This result is common, meanwhile, as suggested by the persistence of both metric and Imperial systems of weights and measures, ${ }^{150}$ the division between CDMA and GSM cellular network technologies in the

143. See, e.g., Cynthia A. Williams, Civil Society Initiatives and "Soft Law" in the Oil and Gas Industry, 36 N.Y.U. J. INT'L L. \& POL. 457, 494-96 (2004) (advocating voluntary environmental regulation of the oil and gas industry given the growth of a global coordination economy).

144. See supra notes 113-15 and accompanying text; $c f$. Robert B. Ahdieh, From Federalism to Intersystemic Governance: The Changing Nature of Modern Jurisdiction, 57 EMORY L.J. 1, 18-21 (2007) (listing multiple authors who have turned to a coordination model in rejecting traditional regulatory models); McAdams, supra note 18, at 256-57 (explaining that while a focus on Prisoner's Dilemma makes regulatory sanctions central, coordination games tend to lead to a focus on nonstate actors and nonregulatory solutions).

145. McAdams, supra note 18, at 210-13.

146. Richard H. McAdams, A Focal Point Theory of Expressive Law, 86 VA. L. REV. 1649, 1710 (2000) (theorizing that where the options are apparent to the participants in a coordination game, "a convention might spontaneously arise in which everyone followed the [efficient] strategy").

147. See supra Part II.B.

148. Id.

149. See McAdams, supra note 18, at 238-39.

150. See Lewis M. Branscomb, The Metric System in the United States, 116 PROC. AM. PHIL. SOC’Y 294, 298 (1972). 
United States and Europe, ${ }^{151}$ and, most broadly, the challenges attendant to the use of multiple languages and currencies among geographically proximate or otherwise closely associated nations. ${ }^{152}$

Even where coordination does occur, it may not be at the optimal coordination point. Recalling the Pareto-ranked Meeting Place game outlined above, this was the result when our two friends met at Penn Station, rather than the more proximate Grand Central Station. ${ }^{153}$ Myriad examples of this species of coordination failure have likewise been offered: our coordination around the purportedly inefficient QWERTY keyboard, the success of the (inferior) VHS over the (superior) Betamax video recording standard, and the long persistence of unanimous action clauses in sovereign debt contracts governed by U.S. law as opposed to the more efficient collective action clauses used in Europe. ${ }^{154}$

Such coordination around an inefficient equilibrium arises from a status quo bias of sorts and the resulting lock-in of a prevailing standard in coordination settings. In the face of coordination dynamics, my preferred coordination point depends on your preference and vice versa, such that our choices are interdependent. Because of this, neither of us is incentivized to abandon even a suboptimal coordination point unless the other abandons it as well.

This, of course, suggests yet a further possibility of coordination failure. Given the interdependence of our strategies, a once-optimal coordination equilibrium may persist, even after some exogenous change has rendered it inefficient. Commonly, such lock-in has been identified in settings where innovation is lacking. After playing a trailblazing role in the early years of software development, for example, Microsoft has come to be perceived as a relative laggard in innovation. ${ }^{155}$ Yet its domi-

151. See Michael R. Franzinger, Latent Dangers in a Patent Pool: The European Commission's Approval of the $3 G$ Wireless Technology Licensing Agreements, 91 CALIF. L. REV. 1693, 1698-99 (2003).

152. Cf. Cristina M. Rodríguez, Language and Participation, 94 CALIF. L. REV. 687, 692-93 (2006) (discussing the challenges posed by multilingualism).

153. See supra note 133 and accompanying text.

154. See Robert B. Ahdieh, Between Mandate and Market: Contract Transition in the Shadow of the International Order, 53 EMORY L.J. 691, 694 (2004); Margaret Jane Radin, Online Standardization and the Integration of Text and Machine, 70 FORDHAM L. REV. 1125, 1132 (2002).

155. See, e.g., Farhad Manjoo, As Browsers Battle, Consumers Stand to Win, N.Y. TIMES, Mar. 26, 2009, at B7, available at 2009 WLNR 5644216. 
nant market share has persisted because of the strong coordination equilibrium around its operating system and other desktop software. ${ }^{156}$ The same story might be told with regard to the use of the wireless spectrum in the United States, which has lagged significantly behind its competitors in relevant innovation. ${ }^{157}$

Given each of the foregoing possibilities, a final potential coordination failure is a kind of barrier to entry. Given the risks of non-coordination or coordination around an inefficient equilibrium, relevant market participants may simply avoid a given market. A prime example of this may be high-definition television. Notwithstanding availability of the necessary technology for decades, HDTV only became commercially available in the last several years. In significant part, this can traced to the hesitation of producers of both equipment and programming to enter the market, given the lack of a common HDTV standard. ${ }^{158}$

There is no lack of potential, then, for significant failures of efficiency in coordination settings. Yet legal scholars have largely ignored the implications of this possibility for the regulatory state. Even in the face of the familiar examples offered above, coordination failures have gone unaddressed by regulation theory.

At least in part, one can trace to the aforementioned sense of coordination as the responsibility of the market. Beyond that, this inattention may arise from a pair of flawed assumptions about the nature and achievement of coordination. The first is the notion that coordination dynamics are inherently nonconflictual. ${ }^{159}$ The world of coordination, in this strikingly widespread view, is limited to the fairly uncommon patterns of pure coordination noted above-which side of the road to drive on, where to find a friend in New York, or the like. The second assumption is that communication constitutes a panacea in coordination settings - that it is both viable and effective in

156. See Allan Hoffman, Predictions and Wishes for the New Year, STARLEDGER (Newark, N.J.), Dec. 31, 2009, at 29, available at 2009 WLNR 26207850.

157. See HELLER, supra note 62 , at 81.

158. See Robert B. Ahdieh, Making Markets: Network Effects and the Role of Law in the Creation of Strong Securities Markets, 76 S. CAL. L. REV. 277, $310-11$ (2003). I will return to these various possibilities of coordination failure infra Part III.B.1.

159. See Russell Cooper et al., Communication in Coordination Games, 107 Q.J. ECON. 739, 765-66 (1992). 
generating efficient coordination results. 160 Each of these assumptions proves false upon closer examination.

The core characteristic of coordination games, once again, is the presence of multiple Nash equilibria. ${ }^{161}$ Such multiplicity of equilibria, however, is not unique to nonconflictual settings. Rather, it can be found in settings of conflict as well. Thomas Schelling, recipient of the Nobel Prize in Economics for his work on coordination games, offered much of this insight in a volume artfully titled The Strategy of Conflict. ${ }^{162}$ Two standard coordination game frameworks help to highlight the potential for conflict amidst coordination.

In each of these settings, players have conflicting interests, but these are trumped by their dominant preference for coordination. Consider the Battle of the Sexes game. A wife and husband have decided to spend an evening together but respectively prefer to go to a boxing match and to the ballet. ${ }^{163}$ In $2 \times 2$ form, with the wife's choice on the vertical axis (and listed first in the payoffs), this account yields the following results:

\begin{tabular}{|l|c|c|}
\hline & Ballet & Boxing Match \\
\hline Ballet & $(5,10)$ & $(-5,-5)$ \\
\hline Boxing Match & $(2,2)$ & $(10,5)$ \\
\hline
\end{tabular}

Self-evidently, the parties' preferences in this case are in conflict. The wife receives a far higher payoff where both go to the boxing match, while the husband receives that superior payoff if they attend the ballet. Multiple equilibria remain, however, with stable and Pareto superior coordination points (i.e., evenings spent together) at either the ballet or the boxing match. Coordination failure is likewise a possibility, where they end up separated-either at their preferred or (in the worse-

160. Id.; see also SCHELLING, supra note 133, at 109-10 (conjecturing that even with full communication, participants in coordination games may still reach unfavorable outcomes).

161. See supra notes $31,35,132,138$ and accompanying text.

162. See SCHELLING, supra note 133.

163. One might alternatively conceive of this pattern as a modified Meeting Place game. Imagine the same separation of friends in New York City described above, see supra notes 134-36 and accompanying text, but with one starting in the vicinity of Penn Station, while the other is near Grand Central Station. 
case scenario) at their disfavored location. Notwithstanding the couple's conflicting preferences, their decisionmaking plays out within a framework of coordination. The dominant preference of both spouses is to be together; each simply prefers a different venue for doing so.

The consistency of conflict with coordination becomes even clearer when we incorporate an even greater degree of conflict. In Hawk-Dove games, ${ }^{164}$ each player must choose between an aggressive pattern of engagement (i.e., playing Hawk) or a deferential strategy (i.e., playing Dove). Higher payoffs accrue to playing Hawk to the other player's Dove, but significantly negative payoffs result from the conflict scenario of a HawkHawk\} strategy. ${ }^{165}$

\begin{tabular}{|l|c|c|}
\hline & Dove & Hawk \\
\hline Dove & $(5,5)$ & $(0,10)$ \\
\hline Hawk & $(10,0)$ & $(-5,-5)$ \\
\hline
\end{tabular}

Even here, we continue to have a coordination dynamic. Notwithstanding the sharp degree of conflict and the countervailing nature of the parties' strategy choices in equilibrium, those who play Hawk-Dove-including teenagers racing their cars toward one another in the game of Chicken 166 -are engaged in a game of coordination. Thus, consider the player on the vertical axis in the payoff matrix, above. If she expects the driver choosing along the horizontal axis to play Dove, she should play Hawk, giving her a payoff of ten. If she expects her counterpart to play Hawk, on the other hand, she should play Dove. She receives no payoff in this scenario, of course, but this is better than the negative payoff of playing Hawk. ${ }^{167}$ Again, we find multiple Nash equilibria from which neither player is incentivized to defect absent a change in behavior by her coun-

164. More colloquially, Hawk-Dove games are known by the name Chicken, in which two cars race toward one another and the chicken is the one who swerves first. Cf. Robert B. Ahdieh, The Role of Groups in Norm Transformation: A Dramatic Sketch, in Three Parts, 6 CHI. J. INT'L L. 231, 261 (2005).

165. See DIXIT \& SKEATH, supra note 110 , at 447-52.

166. Or their tractors, if you prefer, as in Footloose. The version of Chicken played in Rebel Without a Cause has slightly different payoffs, given Jim and Buzz's race toward a cliff, rather than toward each other.

167. In the game of Chicken, thus, it is better to swerve than to crash. 
terpart. The result? The players develop interdependent strategies and experience a coordination game.

Dynamics of coordination, then, are no less salient in the face of conflict. The presence of conflict in real-world coordination settings, such as the financial markets, does nothing to preclude a coordination-game analysis. To be sure, conflicting interests may impact choices of regulatory form, given their introduction of distributional issues not present in the Prisoner's Dilemma or nonconflictual coordination games. ${ }^{168}$ For the same reason, the presence of conflict may impact either the urgency and/or the complexity of relevant regulation. That coordination dynamics are at work in a given area, however, offers no assurance that regulation is unnecessary or superfluous.

This points to the second false assumption behind legal scholars' relative inattention to coordination: a belief that communication will alleviate any potential coordination failure that might arise. ${ }^{169}$ In the pure coordination cases described in the preceding section, an inability to communicate was assumed. Had communication been available, there could be no coordination failure. ${ }^{170}$ With some caveats, this might be said of certain other types of coordination games as well.171

Even in such nonconflictual games, it is important to recognize the limits of communication as we move toward an $n$ person game. With additional participants, the transaction

168. See McAdams, supra note 18 , at 212-13.

169. If we define communication as the distribution of perfect information, it does hold the solution to even conflictual coordination games. For present purposes, however, I am concerned with communication in the more conventional sense.

170. Communication intended to promote coordination may sometimes be foreclosed by regulation itself. Such communication among competitorsincluding under the rubric of standard-setting organizations-might thus be conceived as a collusive violation of antitrust rules. See Mark A. Lemley, Intellectual Property Rights and Standard-Setting Organizations, 90 CALIF. L. REV. 1889,1943 (2002). From this perspective, antitrust law might itself be thought of as regulatory treatment of coordination. It is the flip side of the analysis herein, however, because of its deterrent, rather than facilitative, impact.

171. Even in Stag Hunt (or assurance) games, communication may not eliminate the possibility of coordination failure. As Jean-Jacques Rousseau envisioned such games, a player might abandon coordinated strategies in exchange for a smaller, but more certain, gain. Rousseau explained that, "[i]f it was a matter of hunting a deer, everyone well realized that he must remain faithful to his post; but if a hare happened to pass within reach of one of them, we cannot doubt that he would have gone off in pursuit of it without scruple." JEAN-JACQUES ROUSSEAU, A DISCOURSE IN INEQUALITY 111 (M. Cranston trans., 1984). 
costs of effective communication often increases dramatically. ${ }^{172}$ In choosing a common standard for a given Internet protocol, for example, full communication may be all but impossible. The same might be said of many of the most critical coordination settings.

Thus, the herd behavior and contagion effects at work in financial crises involve far more players than could readily be brought into effective communication with one another. Large numbers likewise plague some subset of the pharmaceutical innovation cases that Michael Heller notes, the processes of peer production suggested by Yochai Benkler, and the copyright dynamics that Larry Lessig cites as obstacles to a robust RW culture. ${ }^{173}$ In the settings of interest to Lessig, even the identification of those with relevant rights may prevent effective communication. Given the wide pool of relevant consumers, many standard-setting decisions will be to similar effect. ${ }^{174}$

Even if the transaction costs of communication among large numbers of relevant actors can be overcome, communication still cannot assure efficient coordination where conflict is present. Consider a standard-setting battle in which relevant

172. See OLSON, supra note 116 , at 18-19. This highlights a distinct framework within which the coordination-driven interactions I emphasize herein might be understood. Richard O. Zerbe, Jr. and Howard E. McCurdy sharply critique the market failure framework within which collective action problems, externalities, and the like are commonly understood-and that my analysis seeks to extend by integrating coordination failures as well. In place of that framework, they favor a transaction-cost analysis of public interventions in the market. In their approach, intervention depends not on the identification of a market failure - be it a collective action problem, an externality, or the coordination failures I add to the conventional litany-but on the government's ability to reduce transaction costs: "In general, anytime government can reduce private transaction costs or its own costs of provision, it should do so regardless of whether or not an externality exists. It need not wait for the appearance of an externality to effect a justification." Richard O. Zerbe, Jr. \& Howard E. McCurdy, The Failure of Market Failure, 18 J. POL'Y ANALYSIS \& MGMT. 558, 565 (1999); see also Richard R. Nelson, Roles of Government in a Mixed Economy, 6 J. POL'Y ANALYSIS \& MGMT. 541, 543 (1987) ("Does it make sense to say that we need government to do these things because of 'market failure'? Or is it more useful to keep in mind that certain functions of government need to be in place for markets to do what we want them to do?'). This account is equally conducive to my emphasis on coordination, if not even more so. Regulatory interventions in the service of coordination-in standardsetting, for example, which Zerbe and McCurdy highlight-may thus be among the most important sources of transaction-cost savings. See Zerbe \& McCurdy, supra, at 572.

173. See supra Part I.

174. In some cases of standard setting, of course, the ability to communicate will suffice to ensure optimal coordination. 
preferences diverge, perhaps significantly. Recurrent standards contests between Microsoft and Google are suggestive. ${ }^{175}$ For each, the promise of a significantly expanded market share favors coordination around a common standard. Alongside this strong desire for a single standard, however, is an equally strong preference for each company to pursue its own interests.

Given such conflicting preferences, communication is no panacea. In the extreme case, it might even reduce the potential for efficient coordination. Consider a modified Battle-of-theSexes game, with payoffs adjusted to reflect a much greater net utility of going to the boxing match. Assume that the wife deeply loves boxing, while the husband's attendance at the ballet is more a matter of social convention than any real interest in pirouettes and the pas de deux.

\begin{tabular}{|l|c|c|}
\hline & Ballet & Boxing Match \\
\hline Ballet & $(5,10)$ & $(-5,-5)$ \\
\hline Boxing Match & $(2,4)$ & $(20,5)$ \\
\hline
\end{tabular}

Given the presence of conflicting interests, communication will not necessarily ensure coordination in the lower-right, $\mathrm{Pa}$ reto-superior quadrant. To begin, any such communication itself will be strategic in nature. Further, such communication plays out in the shadow of whatever salience a given coordination point enjoys, independent of its Pareto superiority or inferiority. Consider each limitation in turn.

In the coordination game at work in any form of bargaining among parties, a party's communications are designed to establish an expectation that her commitment point (the point beyond which she asserts she will not concede further) is in fact her reservation point (the actual point beyond which she will not concede further). ${ }^{176}$ Communication in the Battle-of-the-

175. See Microsoft v. Google: When Clouds Collide, Economist, Feb. 9, 2008, at 69, available at 2008 WLNR 1483992.

176. See Robert B. Ahdieh, The Strategy of Boilerplate, $104 \mathrm{MICH}$. L. REV. 1033, 1051-53 (2006). The limiting factor is the counterparty's own reservation point. It thus accomplishes little to create expectations of a commitment point outside the bargaining zone of one's counterparty. See id. at 1051-52. 
Sexes thus consists of each spouse trying to convince the other-by hook or crook-of his or her unwillingness to go to the disfavored venue. In the presence of this type of conflict, consequently, communication does not assure efficient coordination.

Such strategic communication, moreover, plays out against a backdrop of preexisting focal points for decision. Even if the communications of a particular player do not alter her counterpart's expectations in ways that produce a Pareto-inferior equilibrium, a relevant focal point may lead to that result. If the upper-left quadrant in our Pareto-ranked Battle-of-the-Sexes is focal for some reason-perhaps the ballet is closer to home, the couple already has tickets for it, or some friends will also be attending - it may emerge regardless of any opportunity to communicate. ${ }^{177}$

Ultimately, an optimal strategy may even involve cutting off communication. As Schelling suggests, in a telephone conversation with her husband, the wife in the Battle-of-the-Sexes game might simply declare, "I'm leaving for the boxing match!," and hang up the phone.178 Similarly, in military conflict, a combatant whose preferred position enjoys some focal power might take advantage of a loss of communication to advance her strategic objectives. ${ }^{179}$

Contrary to our standard assumptions, coordination cannot be promised to arise as a matter of spontaneous order, whether because of the limits of communication or the presence of some dimension of conflict. Coordination failures of the sorts described above may therefore emerge. If regulation may consequently have a role to play in coordination settings, what implications follow as to issues of regulatory design? Given the divergence in the justifications for regulation in coordination settings, the form of regulation can likewise be expected to change. With the shift from the Prisoner's Dilemma to coordi-

177. In contract negotiations, I have identified contracting norms to be a potential source of such salience. See id. at 1053-55.

178. See ScHELLING, supra note 133, at 146 "When the outcome depends on coordination, the timely destruction of communication may be a winning tactic. When a man and his wife are arguing by telephone over where to meet for dinner, the argument is won by the wife if she simply announces where she is going and hangs up. And the status quo is often preserved by a person who evades discussion of alternatives, even to the extent of simply turning off his hearing aid.").

179. Beyond the presence of conflict and the limits of communication, incomplete information and uncertainty regarding relevant third parties may be further obstacles to efficient coordination. See DENNIS CHONG, Collective ACTION AND THE CIVIL RIGHTS MOVEMENT 113-14 (1991). 
nation-game dynamics, we must embrace a kind of New Regulation.

\section{THE NEW REGULATION}

Nearly a half-century ago, Charles Reich famously wrote of the emergence of the "New Property."180 In Reich's telling, the ubiquity of the modern administrative state-apparent in the far-reaching tentacles of the welfare system, substantial government employment and contracting, and critical state licensing requirements-had made the state a significant source of wealth and thereby established a new set of property entitlements. With the growing importance of dynamics of coordination in the social and economic order of modern industrialized nations, one might consider the possibility of a similar transformation in the nature of regulation. If a growing proportion of the demands on the regulatory state are grounded in coordination, a New Regulation may be in order as well. 181

If coordination constitutes a distinct justification for regulatory intervention in important areas of the social and economic order, we might likewise expect the form of relevant regulation to be distinct. Of course, one can only analyze this question in a given context. ${ }^{182}$ Minimally, distinct strategic dynamics in one setting versus another, and resulting game structures, will counsel distinct regulatory forms. Even the sources of relevant regulation-the level of government at which intervention occurs and the institution charged with its introduction-might be expected to vary. By parsing through significant dimensions of a shift from preventing defection to facilitating coordination, however, we can discern certain common strands of a coordination-driven regulatory regime.

To that end, this Part considers three shifts in emphasis attendant to a focus on facilitating coordination rather than preventing defection: from altering incentives to shaping expectations, from dominant strategies to multiple equilibria, and from a focus on individuals to an emphasis on groups. To paint a more concrete picture of a coordination-driven regulatory approach, finally, I conclude with a specific application of the framework I suggest. Focusing on the U.S. response to the re-

180. See Charles A. Reich, The New Property, 73 YALE L.J. 733, 787 (1964).

181. To be clear, I do not mean to suggest a precise analogy to Reich's account. His emphasis on the changing function and impact of the regulatory state, however, echoes the argument I make in this Article.

182. See Rubin, supra note 20 , at $1425-26$. 
cent financial crisis, I consider both how that response fares from a coordination perspective and how that response might have been improved upon had the United States better appreciated the centrality of coordination.

\section{A. From Incentives to Expectations}

In the Prisoner's Dilemma, each player's rational response to her individual incentives generates the inefficient result. ${ }^{183}$ In coordination games, by contrast, players' incentives do not dictate any necessary inefficiency. ${ }^{184}$ Nothing in the relevant payoffs predicts suboptimal results. Rather, coordination failure-whether by dint of non-coordination, coordination at a suboptimal equilibrium, or inefficient lock-in-is a result of players' flawed expectations of one another. ${ }^{185}$

The solution to coordination games does not lie in the alteration of incentives, but in the facilitation of accurate expectations of one another. ${ }^{186}$ As Schelling puts it, "[w]hat is necessary is to coordinate predictions, to read the same message in the common situation, to identify the one course of action that their expectations of each other can converge on. They must 'mutually recognize' some unique signal that coordinates their expectations of each other." 187 Expectations are consequently the appropriate target of any regulatory intervention in coordination settings. It is to the shaping of expectations, rather than the alteration of incentives, that coordination-driven regulation speaks. At least three important implications arise from this distinct emphasis. First, it points to a role for various noncoercive regulatory tools and approaches. Second, it suggests the centrality of information in regulatory function and design. Third, it highlights a complex relationship to the efforts of Cass Sunstein and others to address the cognitive biases in decisionmaking observed by behavioral psychology and economics.

\section{Regulation Beyond Coercion}

Conventional notions of regulation see it as inculcating at least some dimension of coercion. It is the very fact of its coer-

183. See DIXIT \& SKEATH, supra note 110, at 274.

184. See McAdams, supra note 18 , at 256-57.

185. See SCHELLING, supra note 133, at 21; Ahdieh, supra note 176 , at 1053; McAdams, supra note 18, at 231.

186. More precisely, it turns on each one's ability to determine what other players are likely to expect of them. See SCHELLING, supra note 133, at 54.

187. Id. 
cion that makes it regulation. 188 This is unsurprising, given the Prisoner's Dilemma conception of the task at hand. Where the regulatory project is to alter the incentives of private actors-in the terms of game theory, to alter the payoffs to different strategies-regulation will ordinarily have some coercive quality. It is in this way that it alters baseline payoffs. ${ }^{189}$

Environmental regulation imposes costs on the creation of pollution externalities to disincentivize their production. The imposition of limits on relevant outputs obviously does so. In recent proposals for a cap-and-trade system for carbon emissions, the intent to alter incentives is even clearer. ${ }^{190} \mathrm{~A}$ similar account can be given of workplace safety, in which employers' competitive incentive to deviate from safety norms is disabled by the Occupational Safety and Health Administration's mandatory standards. ${ }^{191}$

The shaping of players' expectations in coordination settings, by contrast, involves no necessary dimension of command-and-control. A player may alter expectations in any number of noncoercive ways, including cheap talk, signaling, information-provision, and the like. Where the operative question is what each player expects of the other, such noncoercive measures can be quite effective. ${ }^{192}$

Schelling highlighted the function of "focal points" in avoiding potential coordination failures. ${ }^{193}$ Specifically, he posited the existence of some complex cognitive process by which individuals develop coherent expectations of the behavior of others. In the effort of two friends to find each other in New York, for example, Schelling suggested that the focal quality of certain

188. CASS SuNSTEIN, REPUBLIC 2.0, at 159 (2008); Edward Glaeser, Coercive Regulation and the Balance of Freedom, CATO UNBOUND (May 11, 2007), http://www.cato-unbound.org/2007/05/11/edward-glaeser/coercive-regulation-and -the-balance-of-freedom/.

189. See Andrew T. Guzman, A Compliance-Based Theory of International Law, 90 CALIF. L. REV. 1823, 1844 (2002).

190. See Jim Snyder, Budget Includes Cap and Trade Revenues, THE HILL (Feb. 26, 2009), http://thehill.com/homenews/news/18465-budget-includes-cap -and-trade-revenues.

191. See generally Wayne B. Gray \& John T. Scholz, Does Regulatory Enforcement Work? A Panel Analysis of OSHA Enforcement, 27 L. \& SoC. REV. 177, 179 (1993) (discussing incentive structure of OSHA workplace-safety rules).

192. Command-and-control regulation may also shape expectations, of course, if necessarily with a heavier hand. In relevant circumstances, however, it does for reasons beyond its coerciveness.

193. See SCHELLING, supra note 133 , at 57-58. 
locations-be it Grand Central Station or the Empire State Building - could offer a solution. ${ }^{194}$ Given its "salience," 195 some location could be expected to stand out.

Drawing on notions of salience and of a "norm seeding" function for government in facilitating the emergence of efficient social norms, ${ }^{196}$ I have previously described a noncoercive "cueing" role for state authorities in facilitating coordination. 197 Given the relative salience of public initiatives in a coordination setting, such cues might play an influential role in fostering coordination around a particular norm or in displacing an inefficient status quo norm. ${ }^{198}$

In the recent financial crisis, the structuring of public investment in troubled banks and other financial institutions with a clear signal of expected returns might be suggestive of such a noncoercive, cueing approach. By signaling a strong expectation of positive returns, such intervention might help to foster analogous expectations in the market more generally. Information dissemination might play a similar role by highlighting the low price-earnings ratios or sound fundamentals of certain industries. The Treasury Department's facilitation of recurrent engagement among leading banks early in the crisis might also be seen in this light. 199

Targeting assistance to certain lenders and investors, whose return to the markets might be expected to hold relatively greater salience, likewise suggests the power of non-coercive interventions in shaping expectations. The reengagement of such institutions in the markets might influence the expectations of banks, hedge funds, and private-equity firms more generally. A mandate that banks in receipt of public assistance increase lending, by contrast, might not accomplish muchnotwithstanding all the attention that possibility received

194. See id.

195. See ROBERT SuGden, THE ECONOMICS OF RIGHTS, CO-OPERATION AND WELFARE 89-90 (1986).

196. See Randal C. Picker, Simple Games in a Complex World: A Generative Approach to the Adoption of Norms, 64 U. CHI. L. REV. 1225, 1284-85 (1997).

197. See Ahdieh, supra note 38, at 223-25.

198. See id. at 259-61. Examples might include the issuance of reports, the convening of conferences, and the use of the government's purchasing power. In the distinct task of displacing an existing, but inefficient, focal point, another tool might be the development of menus of choices, by which the salience of the status quo equilibrium might be diminished.

199. See Jane Sasseen \& Theo Francis, Paulson Buys Up the Banks, BUS. WK., Oct. 13, 2008, http://www.businessweek.com/election/2008/blog/archives/ 2008/10/paulson_buys_up.html. 
amidst the recent crisis. ${ }^{200}$ Expectations of continued lending and investment seem unlikely to be altered by short-term mandates to do so.

The potential impact of noncoercive interventions in coordination settings, however, is a double-edged sword. Commandand-control regulation, and prescriptive regulation more generally, may not be necessary where coordination is the relevant goal. But the flip side of the coin is equally important to emphasize. In coordination settings, state interventions we might not ordinarily have conceived of as regulation-let alone as candidates for judicial review-may become so.

Consider the government's generation of white papers on various aspects of Internet regulation, ${ }^{201}$ its facilitation of HDTV standard setting by way of the Advisory Committee on Advanced Television Service, ${ }^{202}$ and its convening of representatives of the major Wall Street banks early in the financial crisis. ${ }^{203}$ In each of these cases, the government issued no public mandate and imposed no rules. In a sense, there was no "command" or "control" at all.

Given as much, one might plausibly resist terming such interventions "regulation." Rather, they represent state action of some indeterminate-and implicitly inconsequential-variety. If such interventions have the power to generate focal points in coordination settings, however, they may be no less consequential than coercive regulation in their impact on private behavior. ${ }^{204}$ If so, our conception of what constitutes regulation, and perhaps what we should review as such under the Administrative Procedure Act, may require modification. ${ }^{205}$

200. See David Enrich, Lending Drops at Big U.S. Banks, WALL ST. J., Jan. 26,2009 , at $\mathrm{A} 1$ (suggesting that the decline in lending "raises fresh questions about TARP's effectiveness at coaxing banks to reopen their lending spigots").

201. See, e.g., Appropriate Framework for Broadband Access to the Internet over Wireline Facilities, Policy Statement, 20 F.C.C.R 14,986 (2005).

202. See Ahdieh, supra note 38, at 251-52.

203. See Deborah Solomon et al., Ultimatum by Paulson Sparked Frantic End, WALL ST. J., Sept. 15, 2008, at A1.

204. See McAdams, supra note 146, at 1712 (describing law's effect on behavior not simply as a product of legal sanctions, but from its impact on the environment in which people interact).

205. This highlights a further point. That noncoercive state behavior may have a focal point or coordinative effect tells us nothing about the efficiency of that result. The government may not be particularly good at selecting among alternative coordination points. It may also not be especially timely in doing so. It is for this reason that recognition of the coordinative function of regulation may counsel a broader conception of reviewable state action. 
This, in turn, highlights a further extension in the potential scope of regulation in coordination settings. If coordinationdriven state interventions involve no necessary coercion, then the state's monopoly on force ceases to be a distinguishing characteristic in defining what falls within the universe of regulation. ${ }^{206}$ Even relevant private action might exhibit something in the nature of a "regulatory" effect. If the essential impact of interventions in coordination settings lies in their focal power, certain private actors, given their market power or history as prescient first movers, may possess a coordinative power no less than that of public authorities.

Schelling's theory suggests, for example, the potential for the New York Times to generate a relevant focal point in the Meeting Place game. For friends separated in New York, the appearance of the Empire State Building on the front page of the Times might lead each to expect the other to go there. ${ }^{207}$ Similarly, a bystander with no official authority might assume significant power to direct traffic in a gridlocked intersection, if the traffic lights should fail and no other, more official means of coordination presents itself. ${ }^{208}$ At least in some coordination settings, it may consequently be important to acknowledge, and even review, certain kinds of private regulation as well.

\section{Information as Regulation}

The shift from incentives to expectations as the locus of regulatory design also highlights the critical importance of information in coordination settings. Dynamics of coordination in the financial markets, on the Internet, in technological innovation, and in standard setting are intertwined with issues of information and knowledge. ${ }^{209}$ As such, developments in these areas have been so closely tied to discussions of the emerging "knowledge-based economy" and the "information economy" more generally. 210

206. See Clifford Shearing, Reflections on the Refusal to Acknowledge Private Governments, in DEMOCRACY, SOCIETY AND THE GOVERNANCE OF SECURITY 11, 20-23 (Jennifer Wood \& Benoît Dupont eds., 2006) (explaining that a monopoly over the legitimate use of physical force is a key conceptual component of sovereignty).

207. See SCHELIING, supra note 133 , at 56 .

208. See id. at 144 .

209. See Hal R. Varian, The Information Economy: How Much Will Two Bits Be Worth In the Digital Marketplace?, SCI. AM., Sept. 1995, at 200-01.

210. See, e.g., id. See generally Information Economy Project at George Mason University School of Law, GEO. MASON. U., http://www.iep.gmu.edu (last 
An emphasis on information is not synonymous with coordination games' emphasis on expectations. Expectations are shaped by a variety of factors, some informational and knowledge-based and others more amorphous and less rational in nature. ${ }^{211}$ It is minimally clear, however, that information is a critical influence in the shaping of expectations.

Consider the dynamic at work in standard-setting. Other than where standards are dictated by law, the emergence of new standards depends on some pattern of coordination among relevant market participants. ${ }^{212}$ Sometimes, this dynamic will be driven by market power. A big enough player may essentially dictate the standard that emerges. ${ }^{213}$ Even in these settings, information about the prevalence of alternative standards, their strengths and limitations, and their relative interoperability is likely to remain the lingua franca of the standardsetting process. ${ }^{214}$ In the absence of market power, the importance of such information is even clearer. ${ }^{215}$ In shaping participants' expectations of the likely outcome of the coordination game at work, information about these and other questions can be expected to play a significant role.

An important function for regulatory authorities in coordination settings consequently lies in soliciting, generating, compiling, and distributing technical and market information. ${ }^{216}$ In various high-tech areas, the National Institute of Standards and Technology (NIST), the Federal Communications Commis-

visited Sept. 22, 2010) (studying the interaction of law and economics on the information economy).

211. See Diamond \& Dybvig, supra note 31, at 404 ("[A] bank run in our model is caused by a shift in expectations, which could depend on almost anything, consistent with the apparently irrational observed behavior of people running on banks."); Masson, supra note 36, at 4; T. C. Schelling, For the Abandonment of Symmetry in Game Theory, 41 REV. ECON. \& STAT. 213, 220-21 (1959).

212. See David Singer \& Alexandra Guisinger, Explaining De Jure Versus De Facto Exchange Rate Regime Choices, Mar. 26, 2008 (unpublished manuscript) (on file with author) (paper presented at the 49th annual meeting of International Studies Association in 2008).

213. See infra notes $246-52$ and accompanying text.

214. See Mark A. Lemley \& David McGowan, Legal Implications of Network Economic Effects, 86 CALIF. L. REV. 479, 491-92 (explaining that the increased utility of a large number of users on an operating system will promote migrations to that system, both in terms of users and available applications).

215. See id. at 502 .

216. See Dale A. Osterle, Regulation NMS: Has the SEC Exceeded Its Congressional Mandate to Facilitate a "National Market System" in Securities Trading?, 1 N.Y.U. J. L. \& BUS. 613, 619 (2005) (describing the SEC's goal to design a nationwide system to make market information universally available). 
sion, and other government agencies have played an important role in generating information and facilitating its exchange. ${ }^{217}$ In overcoming the prolonged delay in the commercialization of HDTV technology, for example, the government-established Advisory Committee on Advanced Television Service played a central role. ${ }^{218}$

Similar patterns might be observed in the financial markets. There, information is the coin of the realm, as evident in elaborate securities disclosure regimes that recognize the potential need for regulation to sometimes encourage private production of accurate information in coordination settings. ${ }^{219}$ The very structure of the markets, more broadly, is designed to offer an effective means of informational efficiency. ${ }^{220}$ Regulatory initiatives designed to increase the ease of trading across exchanges, including long-standing aspirations to a National Market System and related requirements of best execution, can be understood in this light. ${ }^{221}$ In each case, relevant rules encourage the exchange of information conducive to efficient coordination.

One can thus expect a regulatory regime oriented to dynamics of coordination in the modern economy to serve important functions in generating, forcing, filtering, and disseminating information. In this account, the NIST, usually considered a backwater of the modern administrative state, potentially emerges as a central player. ${ }^{222}$ The production of white papers,

217. See Ahdieh, supra note 38 , at 251-52.

218. See id.

219. See Joseph Grundfest \& Alan L. Beller, Reinventing the Securities Disclosure Regime: Online Questionnaires as Substitutes for Form-Based Filings 3-4 (Stanford Univ. Law \& Econ., Olin Working Paper No. 361, 2008), available at http://papers.ssrn.com/sol3/papers.cfm?abstract_id=1235082\&.

220. See Ronald J. Gilson \& Charles K. Whitehead, Deconstructing Equity: Public Ownership, Agency Costs, and Complete Capital Markets, 108 ColuM. L. REV. 231, 256 (2008) ("[T] he informational efficiency of public company share prices provides an important management tool-a company receives virtually instant feedback through prices and periodic feedback through analyst reports, concerning its strategy and performance and that of its competitors ....").

221. See Osterle, supra note 216, at 619-23 (2005); Junius W. Peake, Entropy and the National Market System, 1 BROOK. J. CORP. FIN. \& COM. L. 301, 303-04 (2007).

222. The National Institute of Standards and Technology describes itself as a "non-regulatory" federal agency within the Department of Commerce. See NIST General Information, NAT'L INST. STANDARDS \& TECH., http://www.nist .gov/public_affairs/general_information.cfm (last modified Oct. 5, 2010). Its mission is to promote innovation by advancing "measurement science, standards, and technology." Id. 
reports, and standards by the NIST and similar agencies takes on great significance in a coordination-driven account of the functions of the regulatory state. The imposition of reporting requirements by agencies including the Food and Drug Administration, the Federal Trade Commission, and the Federal Communications Commission is to similar effect.223

Where coordination dynamics are the source of relevant demands on the administrative state, information initiatives become critically important. In the shaping of expectations, information will often be essential. It thus constitutes a central feature, not a mere appendage, of the modern regulatory project.

\section{The Behavioral Dimensions of Coordination}

The role of information in coordination settings highlights an important caveat in the regulatory implications of an increased focus on expectations, rather than incentives, as the target of state intervention. Recent years have seen a growing body of work in the field of behavioral law and economics. ${ }^{224}$ Much of this work may soon find application in administrative law and regulation, with the Obama Administration having charged Cass Sunstein with overseeing administrative rulemaking. 225 The coordination dynamics emphasized herein, however, counsel caution in the overly quick embrace of the behavioral remedies that Sunstein and others have pressed. ${ }^{226}$

Over the last twenty years, psychologists and experimental economists have collected significant evidence that the rationality assumption of neoclassical economics fares poorly in the real world. Experimental analysis has highlighted significant cognitive failures, both in information processing (e.g., hind-

223. See, e.g., 21 C.F.R. $\S \S 812.20-.27$ (2010) (requiring applications for the use of a significant risk device in investigations to supply a complete record of prior investigations).

224. See, e.g., Ehud Guttel \& Alon Harel, Matching Probabilities: The Behavioral Law and Economics of Repeated Behavior, 72 U. CHI. L. REV. 1197, 1197-200 (2005); Christine Jolls et al., A Behavioral Approach to Law and Economics, 50 STAN. L. REV. 1471, 1473-76 (1998); Tanina Rostain, Educating Homo Economicus: Cautionary Notes on the New Behavioral Law and Economics Movement, 34 L. \& SOC'Y REV. 973, 973-76 (2000).

225. Brian C. Mooney, Harvard's Sunstein to Oversee Regulation, Bos. GLOBE, Jan. 9, 2009, at 12, available at 2009 WLNR 435653.

226. See THALER \& SUNSTEIN, supra note 101, at 6 (discussing the opportunities and duties presented to "choice architects"). 
sight and availability biases) and in valuation (e.g., the endowment effect). ${ }^{227}$

In the face of these results, scholars of regulation have begun to identify techniques by which regulation might alleviate, work around, or even take advantage of such biases. ${ }^{228}$ Building on this literature, Sunstein and Richard Thaler have argued that government authorities should take advantage of consistent cognitive biases and failures to encourage better individual decisionmaking. ${ }^{229}$ The use of more optimal default rules, the more visible display of healthy goods, and other similar adjustments in what they term our "choice architecture" are offered as valuable "nudges" in individual decisionmaking. ${ }^{230}$

Although Thaler and Sunstein do not explicitly engage with the dynamics of coordination, their ultimate prescription of "nudges" can obviously be seen to echo the account of noncoercive regulation outlined herein. Like my regulatory cues and Randy Picker's "norm seeding,"231 nudges represent a means of substantial, and potentially determinative, regulatory influence, yet with no dimension of coercion.

But a deeper point of intersection between the behavioral law and economics literature and the paradigm of coordinationdriven regulation explored in this Article should also be highlighted. Within traditional, defection-oriented accounts of the social and economic demands on the regulatory state, the cognitive failures identified by behavioral psychology and economics constitute barriers to efficient results. ${ }^{232}$ Broadly, it is my failure to appreciate the losses I will suffer by dint of defection that generates the relevant dilemma.

At least in some coordination settings, however, such failures of rationality hold the key to efficient outcomes. As Thomas Schelling has emphasized, the solution to coordination games will often be more in the nature of art than science. ${ }^{233}$

227. Daniel A. Farber, Toward a New Legal Realism, 68 U. CHI. L. REV. 279, 283-88 (2001). Contra Charles R. Plott \& Kathryn Zeiler, Exchange Asymmetries Incorrectly Interpreted as Evidence of Endowment Effect Theory and Prospect Theory?, 97 AM. ECON. REV. 1449, 1449-50 (2007).

228. For a discussion of how to use cognitive failures and biases to facilitate certain outcomes in tort, see Jolls et al., supra note 224, at 523-32.

229. See THALER \& SUNSTEIN, supra note 101, at 6.

230. See id. at 3-4.

231. Picker, supra note 196, at 1228.

232. See Rostain, supra note 224 , at $990-95$.

233. SCHELLING, supra note 133, at 54-55; see also Diamond \& Dybvig, supra note 31, at 404 (noting that any irrationality can potentially shift the 
Rational decisionmaking does not dictate any given solution to coordination dilemmas. A wife in search of her husband in a department store might look for him at the "Lost and Found" desk, ${ }^{234}$ while friends separated in New York might go the Empire State Building, whether because a picture of it appears in that day's New York Times, ${ }^{235}$ or simply because it is the tallest building in town. Such decisionmaking is not rational, at least in any coherent sense of the word. Yet in avoiding coordination failures, it works.

The optimal regulatory approach to cognitive biases, as a result, may not be as obvious as some of the behavioral literature would suggest. At least in coordination settings, such biases have a valuable role to play. Sunstein and others might therefore do well to be cautious in seeking to regulate around, or otherwise eliminate, our biases.

\section{B. From Dominant StRategies to MULTIPLE EQUILIBRIA}

Echoing the shift in emphasis from incentives to expectations is the related move from dominant to interdependent strategies in coordination settings. ${ }^{236}$ The critical impetus for regulatory intervention in Prisoner's Dilemma settings is the presence of a dominant strategy. Each player is incentivized to defect, regardless of the behavior of their counterpart. ${ }^{237}$ In coordination settings, by contrast, the need for intervention arises from the presence of multiple equilibria. ${ }^{238}$ In coordination games, there is more than one combination of strategies from which neither party is incentivized to shift, absent a parallel shift by the other. ${ }^{239}$

expectations and drive a bank run); Masson, supra note 36, at 4 (describing the notion of "sunspots" in economics as "irrelevant variables that nevertheless coordinate investors' expectations"). Such irrationality is understandably problematic for scientific analysis, formal modeling, and the like. Masson, supra note 36 , at 4 . Nonetheless, that irrationality may be critically relevant for effective coordination.

234. See SCHELLING, supra note 133, at 54, 57.

235. See id. at 57.

236. See Crawford \& Haller, supra note 132, at 572. See generally DIXIT \& SKEATH, supra note 110 , at 233-60 (discussing some counterintuitive results in games with mixed-strategy equilibria).

237. See PoUNDSTONE, supra note 18, at 103-05.

238. Crawford \& Haller, supra note 132 , at 572.

239. As emphasized above, this multiple equilibrium dynamic does not disappear in the presence of conflict. See supra Part II.C. Here, the infamous game of Chicken is starkly suggestive. Surely I prefer to win by not swerving, 
The subsections that follow highlight implications of the multiple-equilibria dynamic at work in coordination settings. To begin, I elaborate on two points already noted above-the potential for coordination failure and the growing range of actions we might see as regulatory in nature. In doing so, I suggest how each turns on the presence of multiple equilibria. ${ }^{240} \mathrm{I}$ then consider the intersections of the coordination account I offer herein with dynamics of innovation. Finally, I suggest a role for regulatory coordination even in Prisoner's Dilemma settings, where the relevant game repeats. Each of these roles, we will see, likewise turn on the presence of multiple equilibria.

1. Multiple Equilibria, Barriers to Entry, and Lock-in in Coordination

Rather than simply a bit of arcane math, the shift from dominant strategies to multiple equilibria emphasizes the distinct regulatory project at work in coordination settings. In the face of collective-action problems, externalities, and other familiar arguments for regulation, relevant interventions seek to alter a dominant strategy of defection. ${ }^{241}$ No issue of defection arises in coordination settings, by contrast, given that no player can gain by abandoning the prevailing coordination point. This is the pattern behind the stickiness of dominant standards, whether in high-tech industries or elsewhere. ${ }^{242}$ It likewise explains the tendency toward strongly dominant networks. ${ }^{243}$ As these examples suggest, however, the presence of multiple equilibria raises its own issues. As outlined above, it generates distinct challenges to achieving and maintaining efficiency, both at the front and back end of the coordination process.

when my opponent does so. I strongly prefer to lose by swerving, however, when my opponent does not swerve. Bluntly put, losing is Pareto superior to dying.

240. For an example of the growing range of actions we might consider regulatory, see supra Part III.A.2. For an example of a potential coordination failure, consider the choice of whether to meet at Grand Central or Penn Central. Supra Part II.B.

241. Cf. Wiley, supra note 127 , at 1916-18 (explaining that the punishments imposed by antitrust statutes will effectively prevent all collusion in a finitely repeated duopoly situation).

242. See Robert P. Merges \& Jeffrey M. Kuhn, An Estoppel Doctrine for Patented Standards, 97 CALIF. L. REV. 1, 6 (2009).

243. See James J. Angel, Consolidation in the Global Equity Market: A Historical Perspective (Feb. 25, 1998) (unpublished manuscript) (on file with author). 
At the front-end, multiple equilibria create potential barriers to entry. ${ }^{244}$ Fear-of-coordination failures of one sort or another may lead relevant actors to resist, or at least delay, entry. Given the potential for non-coordination, or coordination around a suboptimal equilibrium, players may remain on the sidelines for fear of making the wrong choice. ${ }^{245}$

This is especially true when one considers the presence of "tipping effects" in the network and standard-setting areas in which coordination will often be the focus. ${ }^{246}$ Network externalities-paradigmatically captured by the telephone and fax machine-arise in the face of demand-side economies of scale. ${ }^{247}$ Here, the utility of a certain technology-a particular currency, a choice of language, a preferred securities exchange, one DVD standard versus another, or simply the telephone-depends on the size of its network of users. ${ }^{248}$

Given this dynamic, coordination-oriented industries are prone to "tip" to a dominant standard or network. ${ }^{249}$ If the "network value" of a relevant good significantly outweighs its "inherent value," users can be expected to move fairly abruptly to a dominant network, once someone suggests its likely dominance. ${ }^{250}$ The dramatic success of the VHS standard over the

244. Given that "the inability of agents to coordinate their actions successfully in a many-person, decentralized economy" can prevent entry into the labor market, Cooper and John highlight the potential for underemployment equilibria. Cooper \& John, supra note 36 , at 442; see also id. at 451 ("Due to coordination failures, the economy can get stuck at a low level of output.").

245. This result assumes, importantly, the presence of some meaningful cost associated with changing from the initial choice.

246. See Ahdieh, supra note 38, at 226-28 (discussing how tipping effects may cause network competition to become inefficient); cf. Geoffrey Heal \& Howard Kunreuther, Supermodularity and Tipping (Nat'l Bureau of Econ. Research, Working Paper No. W12281, 2006).

247. Mark A. Lemley \& David McGowan, Legal Implications of Network Economic Effects, 86 CALIF. L. REV. 479, 535 (1998).

248. See id. at 483; Howard A. Shelanski \& J. Gregory Sidak, Antitrust Divestiture in Network Industries, 68 U. CHI. L. REV. 1, 5, 59 (2001); see also Michael Klausner, Corporations, Corporate Law, and Networks of Contracts, 81 VA. L. REV. 757, 772 (1995) (noting that some products become more valuable as their use becomes more common, and these products confer benefits to other users, creating a network externality).

249. See supra note 246 and accompanying text.

250. See Ahdieh, supra note 38, at 291-92 ("[W]here the proportion of network value to inherent value in a particular good or service . . . is relatively low, the benefits of the inherent traits of a given good may outweigh the network benefits of its larger competitor, at least for certain users."). 
Betamax alternative has commonly been cited by way of example. ${ }^{251}$

In the face of such tipping effects, two patterns of barrier to entry may arise in coordination settings. First, no player may enter, because of the challenge of accurately predicting which among several potential coordination equilibria will emerge. This, again, is the story of the extended delay in the commercialization of HDTV technology. ${ }^{252}$ This form of barrier to entry is aggravated, moreover, by the relative inability to recoup sunk costs in the presence of strong network or coordination effects. If the preference for coordination in a given setting is sufficiently strong, the limited utility of a non-dominant standard or network may prevent a user or producer of it from making sales, even at well below their marginal cost. 253

A second, more likely form of barrier to entry is the possibility of little entry beyond a first mover. In the presence of tipping effects, we can expect to see strong first-mover advantages. ${ }^{254}$ There may consequently be little barrier to entry by the initial entrant. Thereafter, however, the potential for entry may be dramatically diminished. The seeming persistence of certain technical standards, notwithstanding their dated quality, may be suggestive of this pattern. ${ }^{255}$ In such cases, a first mover may secure sufficient advantage to disincentivize competitive entry.

If barriers to entry constitute a potential market failure at the front end in coordination settings, a further source of inefficiency may present itself at the back end. Whether the equilibrium that emerges at the outset is Pareto superior or inferior,

251. See, e.g., JAGDISH SHETH \& RAJENDRA SISODIA, THE RULE OF THREE: SURVIVING AND THRIVING IN COMPETITIVE MARKETS 15 (2002).

252. See Ellen P. Goodman, Digital Television and the Allure of Auctions: The Birth and Stillbirth of DTV Legislation, 49 FED. COMM. L.J. 517, 522-25 (1997) (discussing the FCC's restriction on DTV access as a means of "ensur[ing] that broadcast television remained a viable option for those who could not or would not pay for subscription video services").

253. See Ahdieh, supra note 38, at 227 n. 45 .

254. See William E. Cohen, Competition and Foreclosure in the Context of Installed Base and Compatibility Effects, 64 ANTITRUST L.J. 535, 550 (1996) ("Adoption of a competitive compatibility standard can yield important network effects. It essentially gives consumers the benefit of other suppliers' networks."); Lemley \& McGowan, supra note 247, at 531, 541 (discussing how "courts have considered network effects in deciding whether or not to grant a new or stronger form of intellectual property protection to the standard setter" and using Lotus Development Corp. v. Borland International, 516 U.S. 233 (1996), as an example of the courts' preference for first movers).

255. See supra note 154 and accompanying text. 
it is likely to be quite sticky. Even where various changes and advances counsel adjustment or displacement of a prevailing coordination equilibrium, the status quo may persist. No assurance can consequently be offered of ongoing efficiency in coordination settings. "[M]utual gains from an all-around change in strategies may not be realized because no individual player has an incentive to deviate from the initial equilibrium." 256

2. Cues, Seeds, and Nudges: The Changing Nature of Modern Regulation

As with the shift from incentives to expectations, the shift from dominant strategies to multiple equilibria similarly highlights the importance of information. In overcoming barriers to entry and lock-in effects, information directed toward the utility and market share of potential alternatives, the preferences of salient users, and questions of compatibility and interoperability may be critical to efficient entry and adjustment.

An emphasis on barriers to entry and lock-in also sheds light on the role of regulation as a signaling device in coordination settings. In these circumstances, regulatory cues, norm seeding, or nudges may play an essential role in facilitating more efficient patterns of entry and exit. 257 By shaping relevant expectations, such cues may effectively overcome barriers to entry and lock-in effects. Among other means, this may be achieved by the dissemination of relevant data and research, the organization of conferences directed to particular coordination questions, advice giving, ${ }^{258}$ and the use of the government's purchasing power. Such measures may, in essence, reduce uncertainty in choosing among multiple coordination equilibria.

If cueing, seeding, and nudging functions are important means of overcoming barriers to entry and lock-in in coordination settings, some adjustment in our conceptions of the scope of relevant regulation may be needed. I have already discussed the potential role of private actors in facilitating coordination, as well as the need to recognize some incidents of noncoercive

256. Cooper \& John, supra note 36 , at $442-43$.

257. See supra text accompanying notes 196-98, 226-34.

258. See Neal Kumar Katyal, Judges as Advicegivers, 50 STAN. L. REV. 1709, 1715-20 (1998), construed in Robert B. Ahdieh, Between Dialogue and Decree: International Review of National Courts, 79 N.Y.U. L. REV. 2029, 2076 (2004). For a discussion of judicial advice-giving as an alternative to judicial review, see Ahdieh supra. 
public action as state action of a sort. ${ }^{259}$ A particular category of the latter, perhaps especially relevant in overcoming barriers to entry and lock-in, arises where the state functions as a market participant. In our constitutional jurisprudence, we have carefully parsed these occasions out of the universe of state action. ${ }^{260}$ In these circumstances, the argument goes, the government may be bigger than others, but it is no different in kind.

One might even expect mere participation in the market to impact expectations in coordination settings. Consider a competition between competing products-the choice between Lexis and Westlaw online legal databases, for example. Given its relative salience, the decision of the government to favor one standard-in this case, the decision of the U.S. Department of Justice to purchase only Westlaw access-might significantly impact private expectations of the standard likely to prevail in the end. ${ }^{261}$

Government procurement decisions might thus go a long way in addressing potential barriers to entry and lock-in effects in coordination settings. Where some efficient technology is underutilized, for example, public adoption of it might dramatically alter expectations of its potential success. Conversely, if that technology should come to exhibit a degree of lock-in, preventing the emergence of superior alternatives, public procurement of those alternatives might help to diminish the focal power of the still dominant, but dated, technology.

Both where salient private actors generate signals with focal power, and where public authorities function as market participants, it may be necessary to assess the dynamic at work as a species of regulation. Noncoercive as such conduct might be, its impact in coordination settings may warrant a role for procedural and adjudicatory constraint. Even on the public side, this would be a notable shift, by which heretofore nonactionable state action would become subject to review. In the

259. See supra notes 204-08 and accompanying text.

260. See, e.g., White v. Mass. Council of Constr. Emp'rs, Inc., 460 U.S. 204, 206-08 (1983) (construing Reeves, Inc. v. Stake, 447 U.S. 429, 436-39 (1980), and Hughes v. Alexandria Scrap Corp., 426 U.S. 794, 810 (1976)) ("[W]hen a state or local government enters the market as a participant it is not subject to the restraints of the Commerce Clause.").

261. Cf. Paul Norman, The Big Match-Lexis v. Westlaw, 4 LEGAL INFO. MGMT. 90, 96 (2004) (asking if the United Kingdom can safely ditch Lexis and rely solely on Westlaw, but concluding that although Lexis has a larger case archive, it suffers from the absence of a sophisticated indexing system). 
private setting, the result is even more striking. What might be the criteria to determine when private action rises to the level of "regulation"? Problematic as it might be, could we imagine the imposition of procedural constraints akin to those of the Administrative Procedure Act on such private action? Whatever prudence might ultimately counsel in our response to these possibilities, the analysis herein highlights the need to more carefully assess the scope of cognizable regulation.

\section{Regulation and Coordination in Innovation}

If multiple-equilibria-driven barriers to entry and lock-in displace dominant-strategy-driven defection as the impetus for regulation in coordination settings, it is worth considering the implications for issues of innovation. I have already emphasized the general coordination dynamic at work in innovation today. Given both the explosion in patent registrations and the nature of innovation finance, coordination-driven regulation must necessarily be at the center of the process. ${ }^{262}$ But a broader nexus of innovation and the coordination functions of regulation might also be suggested. In coordination settings, we arguably face just the opposite concern as in the Prisoner's Dilemma settings traditionally emphasized in our analysis of regulation. In the latter circumstances, regulation seeks to respond to patterns of excess defection. Suboptimal entry and lock-in of prevailing equilibria, by contrast, might be cast as cases of inadequate defection. In these circumstances, the aim of relevant regulation is to overcome inertia-in a sense, to encourage defection.

An important facet of coordination-driven regimes of regulation might thus be the encouragement of innovation. ${ }^{263} \mathrm{Ex}$ amples might include the financing of basic research and development, the encouragement of relevant linkages and partnerships, the underwriting of patent processes, and the development of common standards, among others. ${ }^{264}$ Whatever

262. See supra text accompanying notes $61-64$.

263. See generally Ronald Hirshhorn et al., Innovation in a KnowledgeBased Economy: The Role of Government, in PRODUCTIVITY ISSUES IN CANADA 789, 789-832 (Someshwar Rao \& Andrew Sharpe eds., 2002).

264. In encouraging the movement away from a dominant practice or norm, one might also imagine an important role for menus generated by public authorities. Cf. Klausner, supra note 248, at 839-41 (noting that corporate law can create menus to promote coordination in network externalities). Such menus of options or alternatives might be expected to help diminish the salience of 
form it might take, such facilitation and encouragement of innovation may constitute an important aspect of the regulatory regime when our focus is on multiple equilibria rather than dominant strategies.

\section{Regulatory Coordination and the Evolution of Cooperation}

As widely noted in the legal literature, evolutionary game theory has suggested the potential for cooperation to emerge out of indefinite iterations of the Prisoner's Dilemma. ${ }^{265}$ With repetition, as Robert Axelrod highlighted, a cooperative strategy of non-defection emerges as a sub-game perfect Nash equilibrium. ${ }^{266}$ This equilibrium is not dominant, given that mutual defection and various mixed strategies are potential equilibria as well. ${ }^{267}$

Where Prisoner's Dilemma settings are characterized by the potential for recurrent engagement over some indeterminate period of time, then, we find precisely the multiple equilibria of a coordination game. The Prisoner's Dilemma, in essence, becomes a coordination game. 268 This suggests important extensions of the account of coordination-driven regulation offered herein. To begin, regulatory coordination may have application not only in the coordination settings highlighted in Part I, but in any setting in which a Prisoner's Dilemma might be

the dominant standard, which would presumably be included in any menu, but only as one among numerous potential options.

265. Robert Axelrod famously posited the potential for the "evolution of cooperation" in repeat play Prisoner's Dilemma games. See ROBERT AXELROD, THE EVOLUTION OF COOPERATION 7-14 (1984) [hereinafter AXELROD, EVOLUTION OF COOPERATION]; Robert Axelrod, The Emergence of Cooperation Among Egoists, 75 AM. POL. SCI. REV. 306, 307 (1981) (discussing the appropriate conditions for cooperation to emerge); Robert Axelrod \& William D. Hamilton, The Evolution of Cooperation, 211 SCIENCE 1390, 1391-93 (1981); Michael Trebilcock \& Paul-Erik Veel, Property Rights and Development: The Contingent Case for Formalization, 30 U. PA. J. INT’L L. 397, 412-13 (2008) (discussing Axelrod's game theory approach and how "mutually beneficial cooperative outcomes can arise in a repeated prisoner's dilemma").

266. See AXELROD, EVOLUTION OF COOPERATION, supra note 265, at 10-11 ("[W]ith an indefinite number of interactions, cooperation can emerge.").

267. See id. at 45-46 (discussing various strategies that may lead to cooperation); CHONG, supra note 179, at 39-42 (describing the strategy of mutual defection working itself into a pattern of cooperation).

268. See, e.g., Amnon Rapoport et al., An Experimental Study of Coordination and Learning in Iterated Two-Market Entry Games, 16 ECON. THEORY 661,685 (2000) (pointing to Nash equilibrium as an explanation for tacit coordination in multi-member iterated games). 
subject to repeat plays. ${ }^{269}$ Where collective-action problems or externalities arise in iterative settings, regulation that is noncoercive, information-oriented, and in the nature of cues and nudges may have relevant application.

Consider the prospect of free-riding in the generation of socially useful scientific research-a self-evident public good. In an indefinite repeat-play setting, the incentive of any given citizen to withhold support is diminished by an awareness that others will defect thereafter, depriving all of the relevant benefits. Non-defection-here, support for relevant researchconsequently emerges as a potential equilibrium. In the actual selection of this preferable equilibrium over the alternative of mutual defection, however, noncoercive, information-oriented regulatory cues may have a role to play. As in the more conventional coordination settings outlined above, such coordinative regulation might contribute significantly to shaping expectations of the likely emergence of the Pareto optimal equilibrium of well-funded scientific research. 270

Yet such an embrace of heightened emphasis on coordination suggests an even broader point about relevant regulatory regimes. If Prisoner's Dilemmas become more tractable coordination games when played repeatedly, one might consider a potential role for regulation in encouraging repeat plays in otherwise single-shot Prisoner's Dilemma settings. Regulatory measures designed to encourage repeat interaction might thus be folded into the patterns of a new regulation suggested herein. Tax incentives for joint ventures, code sharing among airlines, and other means of fostering intertwined business relations might thus warrant our attention. ${ }^{271}$ Information generation and dissemination may also play a role. By ensuring the availability of complete information as to the participation

269. This is likewise true where repetition is not indefinite, but there is some operative uncertainty as to the timing of any final play.

270. McAdams, relying on the work of Geoffrey Garrett and Barry R. Weingast, points out a further dynamic of coordination that may emerge with the iteration of a Prisoner's Dilemma game: the choice among alternative policy equilibria around which the parties might coordinate. See McAdams, supra note 18 , at $228-29$.

271. Such tax incentives, of course, fall outside the regulatory paradigm of noncoercive regulation that is not directed to incentives, but to expectations. See supra Part III.A.1. Yet this makes perfect sense. In encouraging the iteration of otherwise single-shot Prisoner's Dilemma games, the dynamic at work at the outset is not one of coordination. A multiple-equilibria coordination game only arises once the game has been rendered iterative in nature. 
versus nonparticipation of individual players, regulatory authorities might strengthen the repeat-play dynamic at work. ${ }^{272}$

Even in the face of familiar Prisoner's Dilemma dynamics in modern social and economic life, then, patterns of coordination-driven regulation may have an increasingly important role to play. ${ }^{273}$ Conventionally, our regulatory response to such settings has been to alter individual incentives to defect, through various coercive measures. When we appreciate the potential transmutation of Prisoner's Dilemmas into coordination games through repeat play, a quite distinct regulatory project is suggested. By facilitating repeat interactions and complete information, regulators may help to facilitate spontaneous order. ${ }^{274}$ At a minimum, such initial interventions may render noncoercive, information-oriented regulatory cues more capable of facilitating efficient results.

Going a step further, one might move beyond a working assumption of fixed payoffs, and a resulting focus on regulation within a game, to consider the role of regulation in changing the game that is being played. Again, John Maynard Smith's evolutionary biology framing of a skulling (Prisoner's Dilemma) versus rowing (coordination) game ${ }^{275}$ is helpful in suggesting the fine distinctions between relevant game structuresdistinctions that regulation might readily insinuate. Here, to be

272. It is worth emphasizing, with regard to these and similarly motivated interventions, that the critical mechanism by which cooperation emerges in the Prisoner's Dilemma is not repetition generally, but repetition that is indefinite or, alternatively, where the timing of any final play is uncertain. Beyond encouraging repeat plays generally, therefore, one might speculate about ways in which a coordination-minded regulatory regime might foster uncertainty as to when ongoing relationships might terminate. Here, competing values are necessarily at stake. Recalling the centrality of information in coordination settings, however, one might imagine a regulatory regime that dictates significant information disclosure upfront, but limits required information sharing thereafter, in such a way that fosters uncertainty of a sort conducive to spontaneous cooperation. $C f$. Charles F. Sabel \& William H. Simon, Destabilization Rights: How Public Law Litigation Succeeds, 117 HARV. L. REV. 1015, 1055 (2004) ("[T]he experimentalist lawmaker does not try to calibrate remedies precisely to induce the desired pattern of conduct, because she does not know with any specificity what the desired pattern of conduct is.").

273. See McAdams, supra note 18, at 229-30 (describing why coordination may be a prerequisite to cooperation).

274. See AXELROD, EVOLUTION OF COOPERATION, supra note 265, at 15556 (noting that in the case of a government and its citizens, the government elicits compliance by "setting and enforcing the rules so that it pays for most of the governed to obey most of the time"). Contract law might plausibly be cast as helping to serve this function.

275. See supra notes $129-30$ and accompanying text. 
sure, we are no longer talking about coordinative regulation. Interventions that create coordination games, on the other hand, are closely linked to the latter.

\section{From Individuals to GROUPS}

Finally, one might see in the move from Prisoner's Dilemma-oriented to coordination-oriented accounts of the regulatory state some shift in emphasis from individuals to groups. Coordination game environments are both characterized and motivated by collective conceptions and commitments of a sort. At heart, coordination dynamics are group dynamics.

At one level, we might say the same of Prisoner's Dilemma games, given their aspiration to understand individual decisions in the context of the strategic choices of others. One might even see this as the goal of game theory, generally. ${ }^{276}$ The dominant strategies that characterize the Prisoner's Dilemma dynamic, however, undercut this account. In the Prisoner's Dilemma, the strategy choice of any given player is independent of any other individual's choice.

In coordination settings, by contrast, each player's choice of strategy is dependent on that of others. If my wife is going to a boxing match, so will I, unhappy as I might be about it. Similarly, if you refuse to swerve in the game of Chicken, I willhowever grudgingly. More tangibly, if I could convince my colleagues to switch to iMacs, I would too. Until then, I continue to type these words on a PC. To similar effect, if Bank of America can get Wells Fargo to resume the extension of credit, and likewise if it cannot.

In shaping regulation in coordination settings, this dynamic proves important. Such regulation is about the group as much as the individual. It seeks to shape group expectations, group strategies, and ultimately group behaviors. In the standard-setting underpinning the Internet, for example, the firstorder question is common embrace of any given standard; its particular nature comes second. A lower-quality but shared standard is thus preferable to the higher-quality standard I use alone.

This points to some intersection between a coordinationdriven account of regulation and the substantial body of recent

276. See, e.g., Francis Fukuyama, Differing Disciplinary Perspectives on The Origins Of Trust, 81 B.U. L. REV. 479, 491 (2001) (suggesting that game theory builds on "a premise of methodological individualism" in order to "question how social cooperation arises"). 
scholarship devoted to the study of social norms. ${ }^{277}$ In that body of work, scholars including Robert Ellickson, Lisa Bernstein, Richard McAdams, Eric Posner, and others have explored the operation of social sanctions, and expectations, in the background of, alongside, and even in conflict with formal law. ${ }^{278}$ In particular, they have highlighted the role of social norms in solving collective action problems. ${ }^{279}$

Social norms might be understood to have particular resonance, however, in settings in which coordination failures are the issue of concern. In facilitating coordination, such norms can play a central role by shaping expectations. On the other hand, the reverse is also true. Recalling the barriers to entry and lock-in problems that stymie efficient coordination, social norms of a sort may often undergird such resistance to optimal coordination. One might even think of coordination equilibria themselves as a kind of social norm. ${ }^{280}$

In the design of regimes of regulatory coordination, then, the importance of group dynamics counsels emphasis on the creation and displacement of social norms. Beyond Picker's "norm seeding," 281 others have explored this pattern as well. Richard McAdams posits a focal point function for law in encouraging coordinated shifts in social norms. ${ }^{282}$ Bob Cooter, by

277. For classic treatments of social norms, see generally DAVID K. LEWIS, CONVENTION: A PHILOSOPHICAL STUDY (1969); SUGDEN, supra note 195; EDNA ULLMANN-MARGALIT, THE EMERGENCE OF NORMS (1977). This scholarship has been revisited and substantially refreshed over the past decade. See, e.g., CRISTINA BICCHIERI, THE GRAMMAR OF SOCIETY: THE NATURE AND DYNAMICS OF SOCIAL NORMS (2006); ERIC A. POSNER, LAW AND SOCIAL NORMS (2000); SOCIAL NORMS (Michael Hechter \& Karl-Dieter Opp eds., 2001).

278. See, e.g., ROBERT C. Ellickson, ORDER Without LAW: HOW NEIGHBORS SETTLE DISPUTES (1991); POSNER, supra note 277; Lisa Bernstein, Opting Out of the Legal System: Extralegal Contractual Relations in the Diamond Industry, 21 J. LEGAL STUD. 115 (1992); McAdams, supra note 146.

279. See Rostain, supra note 224, at 990-91 ("If every group endeavor is potentially prey to a collective action difficulty, it becomes necessary to explain the high degree of observed cooperative behavior. To account for cooperation, law and economics scholarship enlists social norms, which compel people to act cooperatively, despite their individual self-interest.").

280. See Clayton P. Gillette, Lock-in Effects in Law and Norms, 78 B.U. L. REV. 813, 819-20 (1998) (suggesting that if costs are reduced, the Prisoner's Dilemma may be reconstructed as an Assurance Game "in which parties will be willing to move to the new equilibrium because they are confident that a sufficient number of others will").

281. See Picker, supra note 196, at 1284-85 (describing how the government and other entities can create a cluster that grows "until the old convention [is] overrun").

282. See McAdams, supra note 146, at 1671-72. 
contrast, offers an account in which law facilitates the internalization of norms. ${ }^{283}$ For Sunstein, finally, law may foster "norm cascades" in which tipping effects produce quick displacement of a prevailing norm. ${ }^{284}$ In these and other ways, a regime of regulatory coordination might effectively engage social norms in the encouragement of efficient coordination.

A further implication of the shift from an individual to a group orientation in coordination settings is a potential shift in the role of regulatory interventions nominally directed to individuals. Where coordination rather than defection is the impetus for regulation, regulatory constraints on individuals might still occur yet be directed to distinctly different ends. ${ }^{285}$ In such settings, interventions might be less ends unto themselves than means to our desired goals. Where we regulate an institution's use of a particular technical standard or securities trading system, our priority may not be the incentives and resulting strategy choices of that individual institution. Rather, we might expect the latter's choices to alter expectations, along the lines described above. By preventing a salient player on the financial markets from executing block trades of a certain size on a given exchange, we may be less concerned with that particular institution's choice of trading platform than with the signal its use of the relevant system might send to others. ${ }^{286}$

This too might be connected back to the social norms dynamic discussed above. One might thus imagine command-andcontrol regulation not motivated by a desire to change a given individual's behavior but by a wish to reduce the salience of a prevailing social norm. By coercing one market participant to abandon a dominant social norm, its stability might be diminished.

A further source of the more collective dynamic at work in coordination settings goes to the potential distributional issues at stake in the latter. By comparison with the Prisoner's Dilemma, where interventions are ordinarily understood to generate equal utility for all parties, the choice among alternative coordination equilibria will often, as suggested above, favor one

283. See Robert Cooter, Expressive Law and Economics, 27 J. LEGAL STUD. 585, 586-89 (1998).

284. See Cass R. Sunstein, On the Expressive Function of Law, 144 U. PA. L. REV. 2021, 2032-33 (1996).

285. See Ahdieh, supra note 38, at 282.

286. See id. at 279-84. 
party over another. ${ }^{287} \mathrm{~A}$ purely individualistic analysis may constitute, for that reason, an incomplete window into the issues at stake. 288

Most broadly, a stronger orientation to group dynamics in coordination settings might be seen to challenge the methodological individualism that underpins neoclassical economics and the law and economics derived from it. ${ }^{289}$ According to the latter, the operative unit of analysis in the study of economic, social, or political phenomena must be the individual. ${ }^{290}$ One must ultimately reduce the analysis of institutions from the state to the market to the story of individual incentive and rational choice.

In a number of ways, such methodological individualism is under pressure today. ${ }^{291}$ The growing literature directed to network effects is suggestive. In its focus on demand-side economies of scale, the network literature essentially speaks to a world in which individual utility curves cannot be meaningfully disaggregated from social consumption of a given network good. The individual benefits of a telephone, fax machine, online social network, or securities exchange thus depend on its consumption by others. ${ }^{292}$ To talk about the individual utility of a network good, as such, misses at least as much as it captures.

287. See McAdams, supra note 18, at 218-20.

288. Distinctly, the greater distributional problems in coordination settings might be seen as an argument against intervention in coordination versus Prisoner's Dilemma dynamics.

289. See Herbert Hovenkamp, The Limits of Preference-Based Legal Policy, 89 NW. U. L. REV. 4, 33 (1994); Gary Lawson, Efficiency and Individualism, 42 DUKE L.J. 53, 56 (1992); Robert B. Ahdieh, Beyond Individualism in Law and Economics 4 (2010) (unpublished manuscript) (on file with author). On the grounding of standard law and economics in neoclassical economics, see, for example, Jolls et al., supra note 224, at 1545 , and Martha C. Nussbaum, Flawed Foundations: The Philosophical Critique of (a Particular Type of) Economics, 64 U. CHI. L. REV. 1197, 1197 (1997).

290. See Kenneth J. Arrow, Methodological Individualism and Social Knowledge, 84 AM. ECON. REV., May 1994, at 1, 1; Lars Udehn, The Changing Face of Methodological Individualism, 28 ANN. REV. SOC. 479, 489 (2002).

291. Besides the literatures outlined below-studies of network effects, the social nature of knowledge, social norms, and coordination games - other relevant research areas might also be noted in this vein, including analyses of strategic complementarities and herd behavior. See Cooper \& John, supra note 36 , at 442 (noting the nature of strategic complementarities, as distinct from spillovers, as interactions between actors at the level of strategies rather than merely payoffs).

292. See Joseph Farrell \& Paul Klemperer, Coordination and Lock-In: Competition with Switching Costs and Network Effects, in 3 HANDBOOK OF INDUSTRIAL ORGANIZATION 1967, 1974 (M. Armstrong \& R. Porter eds., 2007). 
The growing emphasis on the place of knowledge in the social and economic order, again in relation to the changing nature of modern technology, is to similar effect. Kenneth Arrow has emphasized the social nature of the production, possession, and very nature of knowledge, explicitly highlighting the challenge this raises for methodological individualism. ${ }^{293}$ "[T]he [role] of technical information in the economy," he suggests, "is an especially significant case of an irreducibly social category in the explanatory apparatus of economics."294

The study of social norms might also be cited in this regard. ${ }^{295}$ Though not quite as sharply in tension with methodological individualism as the study of network externalities and knowledge, here too one finds significant conflict. Social norms, of course, are grounded in the collective practice of some regularity of behavior. Such a regularity becomes a norm, in turn, where it is followed with some sense of obligation. Analysis of the collective, as such, is critical to an understanding of social norms.

The coordination-driven analysis advanced herein, finally, can also be included in this litany. By dint of the interdependence of strategies at the heart of coordination games, they highlight the limits of a rigidly individualistic orientation. If collective expectations are the critical ingredient in the solution to coordination failures, rather than individual incentives, methodological individualism overlooks a critical dimension of the analysis.

To be clear, none of these literatures directly undermine the claim of methodological individualism, since each might well be framed in the reductionist terms it prescribes. The coordination game literature, like game theory generally, is ultimately directed to the strategic choices of individuals. 296 That said, when considered as a collective whole, the study of network effects, the social nature of knowledge, social norms, and coordination games represent a meaningful challenge to the sufficiency of methodological individualism's account. Individu-

293. See Arrow, supra note 290, at 1 ("I want to argue today that a close examination of even the most standard economic analysis shows that social categories are in fact used in economic analysis all the time and that they appear to be absolute necessities of the analysis, not just figures of speech that can be eliminated if need be.").

294. Id.

295. See Lawrence A. Cunningham, Beyond Liability: Rewarding Effective Gatekeepers, 92 MINN. L. REV. 323, 337 n.75 (2007).

296. See Udehn, supra note 290 , at 483 . 
als may well remain the basic unit of analysis, but in the design of effective regulatory regimes, a focus on groups may be critical as well.

\section{CRISIS AND CoORdination IN THE FinanCial MarketS}

It is beyond the scope of the present analysis to play out the full implications of the foregoing principles of a coordination-driven regulatory regime. This is especially true given the dependence of any such assessment on a context-specific "microanalysis" of institutions-an analysis sensitive to the distinct dynamics of coordination at work in any particular regulatory setting. ${ }^{297}$ Given the salience of the recent financial crisis as an example of coordination dynamics in the modern social and economic order, however, it may be useful to conclude by suggesting implications of the above for our response to such crises.

Most obviously, this Article emphasizes failures of coordination rather than defection to be at the heart of financial crises. For all the attention lavished on executive bonuses and compensation, ${ }^{298}$ on Bernie Madoff ${ }^{299}$ and Allen Stanford, ${ }^{300}$ and on the need to address the exploding rate of foreclosures, ${ }^{301}$ none of these were at the core of the financial crisis. ${ }^{302}$ At its heart, rather, stood a failure of lending and investment.

More precisely, it was a problem of multiple equilibria. As outlined above, financial markets are characterized by alternative potential equilibria - one defined by the extension of credit, by investment, and by growth, and the other by the denial of credit, curtailed investment, and economic contraction. ${ }^{303}$ The core challenge for financial market regulators is consequently how to avoid the shift to a suboptimal equilibrium when the market is healthy and, when crises nonetheless occur, how to

297. See Rubin, supra note 20, at 1425-26.

298. See, e.g., Andrews \& Bajaj, supra note 24, at A1.

299. See, e.g., Healy, supra note 24, at 5.

300. See, e.g., Clifford Krauss et al., Fraud Parade: $\$ 8$ Billion Case Is Next in Line, N.Y. TTMES, Feb. 18, 2009, at A1, available at 2009 WLNR 3130330.

301. See Vikas Bajaj, Responding to a Housing Crisis, N.Y. TIMES, Aug. 26, 2008, at C1, available at 2008 WLNR 16086145.

302. To be clear, I do not mean to suggest these were not grave issues in their own right. Given its scope, the foreclosure crisis likely warrants even more attention than it has received. I likewise recognize the secondary impact of these varied market failures on credit markets. They do not speak directly to the financial crisis, however, and hence to the recovery of the financial markets.

303. See supra Part III.B.2. 
shift the market back in the other direction. How do regulatory authorities displace barriers to entry in the credit and investment markets, overcoming lock-in of the suboptimal equilibrium of noninvestment? Ultimately, this is a question of expectations: how can the Federal Reserve Bank, the U.S. Treasury, and even the White House shift market participants' expectations of the likely lending and investment practices of other market participants? ${ }^{304}$

If the resolution of financial crises lies in such an adjustment of expectations and a resulting shift to the Pareto superior equilibrium of lending and investment, what policy implications follow for the State's response to financial crises? One is the relatively more limited, or at least distinct, role it suggests for coercive regulatory interventions such as the much-debated possibility of mandating lending by recipients of federal bailout funds. ${ }^{305}$ If the operative task is to adjust the expectations of banks and hedge funds as to the likely lending and investment practices of other banks and hedge funds, such prescriptive regulation may have a limited place. Notwithstanding its alteration of subject banks' incentives, its impact on expectations more broadly seems likely to be limited. In a coordination setting, however, it is primarily that indirect impact that would justify its imposition.

If the critical regulatory need in the financial crisis lies in cues designed to shape expectations rather than in the coercive alteration of incentives, what might qualify as such cues or nudges? One example might be the bank "stress tests" conducted by the U.S. Treasury in early 2009.306 As irrelevant to incentives as this initiative was, and as ambiguous as were the implications of a bank's failure, the significant attention to the tests might be understood by reference to their role in shaping expectations. If the federal government could systematically

304. A further dimension of the government's task to facilitate coordination amidst the recent financial crisis lies in the structure of the credit markets, by which a bank's lending is dependent on its ability to market its securitized debt to hedge funds and private equity firms. See supra notes 25-40 and accompanying text. Some dynamic of coordination consequently exists across distinct categories of banking and private investment entities as well.

305. Again, I do not wish to suggest that such coercion does not have its place in addressing fraud, excessive risk taking, and analogous defections from efficient equilibria —or that such defections are uncommon.

306. See Deborah Solomon \& Jon Hilsenrath, Bank Capital Gets Stress Test, WALL ST. J., Feb. 26, 2009, at A3. 
separate out the wheat from the chaff, perhaps investors might expect that they could do so as well.

One might cite the gathering of bank representatives as another tool in shaping relevant expectations. Though convened early in the financial crisis, ${ }^{307}$ a greater frequency of such gatherings may have been useful. Wider participation by the hedge funds and private equity firms on which banks were dependent for their continued lending would likewise have been beneficial. In coordinating relevant expectations, such broader gatherings may well have played a valuable role.

Beyond these two, other regulatory cues of relevance to the resolution, and perhaps the avoidance, of financial crises might also be suggested. As evident in the financial market's close attention to Alan Greenspan's every word during his tenure as chair of the Federal Reserve Bank, and to the Kremlin-esque minutes of the Fed's Open Market Committee, official statements on the markets have the potential to play a vital role in facilitating desirable coordination. 308 Though cheap talk, they may be a significant factor in any movement between optimal and suboptimal equilibria. The careful use of such statements-by the President, the Chair of the Federal Reserve, and the Secretary of the Treasury Department-may be crucial.

Regular statistical reporting on the state of the markets might serve a similar function. A well-designed regime of regulatory coordination in the financial markets, however, would need to carefully consider the appropriate frequency of such reporting. In the shaping of expectations amidst a financial crisis, some data might benefit from more frequent collection and dissemination. Other information might better be offered with less regularity. ${ }^{309}$

A final category of potential regulatory cues in financial crises would be efforts to increase the salience of market behavior inconsistent with a prevailing equilibrium of non-lending

307. Cf. Andrew Ross Sorkin, Merrill Is Sold; Failing to Find Buyer, Lehman Set to File for Bankruptcy, N.Y. TIMES, Sept. 15, 2008, at A1 (describing various actions taken by Wall Street firms in response to the financial crisis).

308. See Shares Edge Higher as Greenspan Offers Positive Outlook, N.Y. TIMES, July 21, 2004, at C7, available at 2004 WLNR 5599926; cf. ELLYN BOUKuS \& JOSHUA V. ROSENBERG, THE INFORMATION CONTENT OF FOMC MINUTES 1-5 (2006), available at http://www.newyorkfed.org/research/ economists/rosenberg/Boukus_and_Rosenberg_072006.pdf.

309. This need not correlate with the likelihood that some reports versus others will offer better news. Rather, the notion is that some types of shortterm information may be more prone to impact expectations in harmful ways. 
and non-investment. Some banks continued to lend, even amidst the crisis. Some funds continued to invest. In each case, profits were made. By emphasizing such activity, perhaps in the particular, regulators may diminish the salience of the prevailing equilibrium of non-lending and non-investment. In the best of all possible worlds, they might even re-establish lending and investment as a focal point for coordination.

Beyond these particular approaches, several broader points also deserve emphasis. To begin, there is the critical importance of consistency. This is true of command-and-control regulation as well. ${ }^{310} \mathrm{But}$, in a regulatory regime directed to the shaping of expectations, it is especially crucial. The U.S. response to the financial crisis may be a mistake to learn from in this regard. Much of the market's failure to respond to the government's various initiatives through 2008 and 2009 might be blamed on the inconsistency of those policies. The purchase of banks' toxic assets, the lending of significant funds to financial institutions, the extension of credit to hedge funds and private equity firms, and even the threat of nationalization might each have effectively loosened the credit markets, had any of these options been pursued consistently. Without that consistency, on the other hand, they were doomed to fail. Why? Because the shaping of expectations is, by very definition, an exercise in consistent and accurate prediction. ${ }^{311}$

Further dimensions of the coordination function of regulation in financial crises turn on the aforementioned role of government as market participant and on the role of relevant private behavior. ${ }^{312}$ As to each, there is no dimension of coercion. Yet each may have a substantial role to play in shaping relevant expectations.

Recall the basic notion that government purchasing decisions may impact expectations of the potential for a given standard, technology, or network to succeed. This is just the no-

310. By comparison, inconsistent prosecution of legal or regulatory violations may be effective if coupled with some indeterminacy as to the occasions for prosecution and sufficiently severe penalties, when it occurs.

311. One might criticize Treasury Secretary Timothy Geithner's initial presentation of the Obama Administration's financial market rescue plan along analogous grounds for its vague and undefined terms. See Deborah Solomon, Market Pans Bank Rescue Plan, WALL ST. J., Feb. 11, 2009, at A1, available at 1995 WLNR 3801017. In the shaping of expectations, again, certainty and predictability may be especially essential.

312. I have already emphasized the potential role of private actors in facilitating coordination. See supra notes $206-08$ and accompanying text. 
tion at work in the government's investment in firms from IndyMac Bank and General Motors to Citibank and AIG. Where the emphasis is on shaping the expectations of market participants, however, we might favor investment and payout structures that suggest relatively stronger expectations of reimbursement and even positive returns. ${ }^{313}$ Going a step further, hard bargaining by the U.S. Treasury in the negotiation of such bailout deals might offer a relatively more effective signal by more closely mimicking the behavior of the private investors whose expectations such public investment must ultimately change.

As to private actors, an expectation-oriented coordination account holds similarly notable implications. Notwithstanding the diminished need for coercion in shaping expectations, it may have a place where the lending or investment practices of a particular firm (e.g., Goldman Sachs) has special salience in the market. Firms with particular potential to impact market expectations might be seen as plausible candidates for targeted coercive interventions of one sort or another. Coerced or otherwise incentivized lending or investing by such firms might thus play a salutary role-not as an end unto itself, but to prompt lending and investment by others. One might imagine, from this vantage, the subsidization of a salient firm's unilateral shift to a practice of lending or investment. Even at substantial cost, such a shift might serve a focal point function in facilitating a broader (if not especially rational) shift in expectations to renewed lending and investment.

In fostering coordination amidst financial crises, a further point to recall is the central role of information. Each of the lines of action suggested above incorporates at least some dimension of information generation and distribution. This raises an interesting question, though, as to the appropriate approach to information dissemination amidst coordination-driven financial crises. If the operative goal is to shift expectations toward the preferred lend/invest equilibrium, one might plausibly argue for a strategy of selective information dissemination, in which the government only exposes positive information to the

313. Consider the case of the 1994 bailout of the Mexican peso, on which the United States turned a profit. See Anthony DePalma, Mexican Rescue Plan: The Overview, N.Y. TIMES, Feb. 2, 1995, at A1. One might see the government's relatively quick resale of IndyMac Bank, subsequent to its takeover, in a similar light. See Equity Partnership is Formed to Buy Remnants of IndyMac Bank for $\$ 13.9$ Billion, N.Y. TIMES, Jan. 3, 2009, at B3. 
light of day. As suggested by the role of official statements and the collection and distribution of market data, there is surely some wisdom in this approach. Yet, it is important to recognize its limits. The role of subprime securities in the recent financial crisis highlights as much.

At least in some part, one can trace the contraction of the credit markets in 2008 and 2009 to the diminished value of these toxic assets following the collapse of the U.S. housing market. Given the limited volume of such securities as a proportion of the total assets of the largest financial institutions, on the other hand, this explanation cannot suffice. Much of the shift in expectations thus lay in uncertainty as to the extent of exposure of any given financial institution to these investments. Dating back to the collapse of Bear Stearns in March 2008 , it was the unknown scope of liability, as much as anything else, that prevented the effective pricing of assets and institutions and thereby precipitated the credit crunch.

Whether rosy or gloomy, therefore, information may be critical to the alleviation of financial crises. Whether an asset or institution is worth pennies or its weight in gold, it can be effectively bought or sold when its worth is known. Only when its value is unknown ought we to expect investors to rationally sit it out.

In handling the toxic assets generated by the housing market's collapse, therefore, the generation and dissemination of accurate information might have been even more important than removal of relevant securities from financial institutions' books. 314 Welcome as the latter might have been to those institutions, it was relatively less crucial to alleviating the financial crisis. Facilitation of necessary forensic accounting might have been a more useful first step. Government-sponsored auctions may likewise have served a role in helping the market generate accurate price information on distressed assets. 315 Whatever the precise mechanism, even the generation of adverse information may be important to the salutary shaping of expectations amidst financial crises.

314. Cf. Campbell R. Harvey, The Financial Crisis of 2008: What Needs to Happen After TARP 2-9 (Oct. 5, 2008) (unpublished manuscript), available at $\mathrm{http}: / /$ ssrn.com/abstract $=1274327$.

315. Cf. Edmund L. Andrews, Bank Crisis Deepens, N.Y. TIMES, Jan. 21, 2009, at B1, available at 2009 WLNR 1150590 (explaining the difficulties faced by the Obama Administration in planning the recovery from the financial crisis). 
That said, the role of cold, hard information in shaping expectations should not be overstated. Important dimensions of expectation formation are non-rational in nature and have little to do with information as such. ${ }^{316}$ Perhaps especially with regard to the financial markets, where Keynes spoke of the power of "animal spirits,"317 a coordination-oriented regulatory regime does well to acknowledge the place of irrationality. Here, it is especially difficult to offer a coherent account of possible elements of a relevant regulatory scheme. The lesson of coordination, in fact, may lie in just the opposite notion. An effective regulatory approach to financial crises must recognize the potential for non-rational factors to play a significant role, and be willing to take advantage of such factors where possible. Whether it is the adjustment in expectations prompted by a dominant market participant's decision to lend or invest, the potential for a similar response to the decision of a competitor to do so, or broader tendencies toward herd behavior, nonrationality may be an important element in coordination-driven responses to financial crises.

Finally, by way of this thumbnail sketch of a coordinationdriven regulatory approach to financial crises, we should recall the need for regulators to attend closely to group dynamics. Most tangibly, one might see this in the aforementioned role of gatherings of relevant market participants in shaping coordinated expectations. A group conception of the regulatory project amidst financial crises likewise underlies the possibility of targeted incentives-whether carrot or stick-to encourage lending or investment by salient market participants. In such cases, individual behavior is not an end unto itself. It becomes simply a means to the ends of an adjustment in group expectations.

\section{CONCLUSION}

Nearly a half-century ago amidst dramatic changes in the nature of the regulatory state and its place in the social and economic order, Charles Reich highlighted the emergence of a "New Property." 118 Decades later, changes in our social and economic life counsel recognition of a New Regulation as well. Dynamics of coordination stand at the heart of life in the modern industrialized state. In the financial markets, the operation

316. See supra Part III.A.3.

317. See KEYNES, supra note 38, at 161-62.

318. See Reich, supra note 180 , at 787. 
of the Internet, standard-setting processes, the building of telecommunications, transportation, and social networks, and the encouragement of innovation, effective coordination is among our most critical challenges. Given the increasing significance of so many of these areas, moreover, we can only expect the importance of coordination to grow in the years ahead.

It is essential, then, that our theories of regulation keep up. The lack of emphasis on coordination in our standard accounts of the role and function of the regulatory state is no longer sustainable. To the contrary, we need an affirmative theory of the role of regulation in a coordination economy. This need not be seen as displacing the need to address our traditional fears of individual or institutional defection. Even the fundamentally coordination-driven financial crisis was characterized by significant incidents of defection-style market failure-from the high-risk investments of AIG to the massive fraud perpetrated by Bernie Madoff. Coordination must simply be added alongside defection as a source of concern for the regulatory state.

Whatever the extent and nature of a regulatory regime attuned to coordination, what is minimally clear is that it deserves our closer attention. Coordination stands at the heart of many of the most important - and most chaotic - areas of modern regulation. If our regulatory approach to these modern challenges is to succeed, the study of coordination must move to the center of regulation theory. 